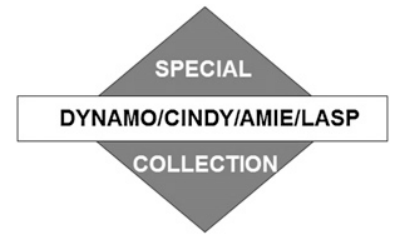

\title{
Wind-Flux Feedbacks and Convective Organization during the November 2011 MJO Event in a High-Resolution Model $\mathscr{O}$
}

\author{
Emily M. Riley Dellaripa, ERic Maloney, AND Susan C. VAN DEN HeEver \\ Department of Atmospheric Science, Colorado State University, Fort Collins, Colorado
}

(Manuscript received 30 November 2016, in final form 15 August 2017)

\begin{abstract}
The November 2011 Madden-Julian oscillation (MJO) event during the Dynamics of the MJO (DYNAMO) field campaign is simulated with the Regional Atmospheric Modeling System (RAMS) cloud-resolving model to examine the relationship between precipitation and surface latent heat flux (LHFLX) for deep convective clusters within the MJO and to discern the importance of surface LHFLX for organizing MJO convection. First, a simulation similar in size to the DYNAMO northern sounding array was run with interactive surface fluxes. Composites for precipitation, surface LHFLX, wind speed, wind vectors, and near-surface specific humidity are described for various-sized convective clusters during different MJO regimes. The precipitationLHFLX relationship generally evolves as follows for an individual cluster. About $2 \mathrm{~h}$ before cluster identification, the maximum LHFLX occurs upwind of maximum precipitation. As cluster identification time is approached, LHFLX and precipitation maxima become coincident. At and after the cluster is identified, maximum LHFLXs move downwind of the precipitation maximum with a local minimum in LHFLXs behind the precipitation maximum.

Sensitivity simulations with spatially homogenized LHFLXs were then run to determine the impacts of local LHFLX feedbacks on convective organization. Using area-averaged convective versus stratiform precipitation fraction and a simple convective aggregation index to quantify organization, no systematic difference in convective organization was detected between the control and sensitivity simulations, suggesting that local LHFLX variability is not important to convective organization in this model. Implications of these results are discussed.
\end{abstract}

\section{Introduction}

The elusive understanding of the Madden-Julian oscillation (MJO) continues to push the forefront of understanding tropical moist convection with regards to spatial- and temporal-scale interactions, air-sea feedbacks, teleconnections, and various other topics. This concentrated focus is driven by lack of a complete theory that explains the MJO initiation, growth, propagation, and spatial scale, as well as the failure of most general circulation models (GCMs) to accurately simulate MJO events [see reviews by Madden and Julian (1994) and Zhang (2005)]. Building on previous observational, theoretical, and modeling work, the research

\footnotetext{
Supplemental information related to this paper is available at the Journals Online website: https://doi.org/10.1175/JAS-D-160346.s1.
}

Corresponding author: Emily M. Riley Dellaripa, emily@atmos. colostate.edu described in this paper aims to assess the role of convective-scale wind-induced surface flux feedbacks in supporting convective clusters within the MJO and determine how important this feedback is for subsequent convective organization.

Several hypotheses attempting to explain the observed physical characteristics of the MJO assert that moisture is integral to MJO development and/or maintenance. For example, the wind-induced surface heat exchange (WISHE) hypothesis states that a positive feedback between winds, surface fluxes, and MJO convection exists (Emanuel 1987; Neelin et al. 1987; Sobel et al. 2010). Although the original linear WISHE theory of Emanuel (1987) and Neelin et al. (1987) has been largely disproven, as enhanced surface fluxes and convection occur in low-level westerlies instead of easterlies as the original theory predicted, nonlinear WISHE is still viable (Sobel et al. 2010). Moisture is also integral to the moisture-mode hypothesis (e.g., Raymond 2001; Sobel and Maloney 2012, 2013). Feedbacks among surface fluxes, radiation, and cloud processes can conspire 
to maintain free-tropospheric moisture and enhance convection against the drying and dissipating effects of vertical and horizontal advection (e.g., Sobel et al. 2001).

Despite decades of research, most GCMs fail to simulate MJO events with fidelity (e.g., Kim et al. 2014; Jiang et al. 2015; Klingaman et al. 2015). DeMott et al. (2015) argued that GCMs that include air-sea feedbacks tend to better simulate the MJO because these models generally capture a more realistic relationship between precipitation, surface fluxes, and sea surface temperature (SST), suggesting that surface fluxes may be an important modulator of MJO development and propagation. Sobel et al. (2010) synthesized observational and GCM sensitivity results to advocate for a more thorough examination of the importance of wind-induced surface flux feedbacks to MJO convection. Their GCM sensitivity tests found that the amplitude of the MJO was reduced when windevaporation feedbacks were disabled, similar to the findings of Maloney and Sobel (2004), Maloney and Esbensen (2005), Sobel et al. (2008), and Maloney et al. (2010).

Previous observational work has shown that surface latent heat fluxes (LHFLXs) are positively correlated with precipitation on intraseasonal time scales (Maloney and Esbensen 2003, 2007; Araligidad and Maloney 2008; Kiranmayi and Maloney 2011; Riley Dellaripa and Maloney 2015, hereafter RDM2015). In the context of moisture-mode theory, observational estimates of the magnitude of intraseasonal surface flux anomalies relative to precipitation indicate that they are an important, though perhaps not sufficient, anomalous source of freetropospheric moisture for destabilizing the MJO (e.g., Sobel et al. 2014; de Szoeke et al. 2015; RDM2015).

Previous work has generally focused on examining the direct role of surface flux feedbacks for maintaining the large-scale MJO convective envelope through comparison of intraseasonal convection and flux anomalies (e.g., Jones and Weare 1996; Hendon and Glick 1997; de Szoeke et al. 2015; DeMott et al. 2016), although some work has attempted to quantify the importance of interactions between surface fluxes and convective variability at smaller time and space scales, including feedbacks onto the larger MJO convective envelope. The observational work of Maloney and Esbensen (2007), Araligidad and Maloney (2008), and RDM2015 used spatial and temporal averaging to remove the effects of mesoscale and synoptic wind-flux feedbacks on MJO convection in order to assess how these scales contributed to the positive relationship of precipitation and LHFLX at intraseasonal time scales. In all three studies, the regression coefficient between intraseasonal precipitation and LHFLX was slightly reduced when the effects of meso- and synoptic-scale winds were removed, suggesting that mesoscale wind variability has some modest effect on the MJO convective-flux feedback relationship at intraseasonal time scales.

Chuda et al. (2008) and Yokoi et al. (2014) specifically looked at the relationship between radar-observed precipitating systems and surface fluxes within MJO events. Both found that precipitating systems enhance surface LHFLXs primarily through convectively generated increases in wind speed, similar to the findings of Esbensen and McPhaden (1996) and Saxen and Rutledge (1998) for MJO convection during TOGA COARE. Most of the precipitating systems analyzed by Yokoi et al. (2014) were smaller than mesoscale convective systems (MCSs) since their horizontal extent was less than $100 \mathrm{~km}$, which is the Saxen and Rutledge (1998) threshold for MCSs. Composites around these sub-MCS (i.e., horizontal extent $<100 \mathrm{~km}$ ) rain events revealed that surface heat fluxes increased during anomalously active MJO days with LHFLXs dominating over sensible heat fluxes. Chuda et al. (2008) determined that increases in surface fluxes due to precipitating systems contributed significantly to the total change in surface fluxes over the time scale of the MJO, suggesting gustiness associated with individual precipitating systems may affect MJO evolution. Neither study, however, specifically discussed how flux-precipitation interactions influence convective organization.

Independent of an MJO focus, previous studies on convection over tropical oceans have documented the relationship between precipitation and surface fluxes and the role of surface fluxes at organizing convection. Several studies showed the enhancement of surface fluxes associated with convectively generated gust fronts (e.g., Young et al. 1995; Redelsperger et al. 2000; Wu and Guimond 2006). Tompkins (2001) showed that cold pools primarily aid convective organization through thermodynamic effects by reducing convective inhibition (CIN) as a result of surface flux feedbacks. Tompkins and Craig (1998) demonstrated that convective organization within their 3D cloud-resolving model (CRM) runs was degraded when wind-induced surface fluxes were replaced with Newtonian relaxation terms. Opposite results were obtained by Gentine et al. (2016), who found that simulations with fixed surface fluxes had more organized convection than simulations with inhomogeneous fluxes. Using observations, Tobin et al. (2012) found that more aggregated (or organized) convective systems are associated with higher surface fluxes (both latent and sensible) than less aggregated convective systems.

Idealized radiative convective equilibrium (RCE) CRM studies have also examined the importance of surface fluxes for convective organization (e.g., Bretherton et al. 2005; Muller and Held 2012; Wing and Emanuel 2014; 
Wing and Cronin 2016; Holloway and Woolnough 2016). In these studies, convection self-aggregates from a state of scattered to clustered convection as the model domain segregates into a moist area surrounded by a dry area. Bretherton et al. (2005) found that convection did not self-aggregate when their model was initialized with homogenized surface fluxes. Sensitivity simulations by Muller and Held (2012) showed that while surface fluxes were not critical for convective self-aggregation, they did favor self-aggregation. Wing and Emanuel (2014), Wing and Cronin (2016), and Holloway and Woolnough (2016) found that surface fluxes are important in the initial stages of self-aggregation but are not important to maintain aggregation. This led Holloway and Woolnough (2016) to suggest that in the real world, surface flux feedbacks may not be important for organizing convection since the real world always has some degree of convective organization.

In this study, we use a CRM to simulate the November 2011 MJO event that was observed during the Dynamics of the MJO (DYNAMO; Yoneyama et al. 2013) field campaign to examine the relationship between precipitation and LHFLXs for precipitating systems within the MJO. We focus on LHFLX since they dominate the sensible heat fluxes during MJO events (e.g., RDM2015; DeMott et al. 2015). The main objective of this study is to assess the importance of LHFLX feedbacks on the convective scale in organizing MJO convection. Control simulations using interactive LHFLX will be compared to simulations with homogenized LHFLXs to determine the role of wind-induced LHFLX feedbacks in organizing convection. This work extends the evaluation of surface flux feedbacks to the destabilization and maintenance of MJO convection from the MJO-envelope time and space scale (e.g., Sobel et al. 2010; Araligidad and Maloney 2008; RDM2015) to the smaller convective scale. In this study, the convective scale refers to precipitating cloud clusters (defined below) ranging in size from a single model grid point (i.e., $2.25 \mathrm{~km}^{2}$ ) to submesoscale (i.e., cloud system area $<2000 \mathrm{~km}^{2}$; Yuan and Houze 2010) to mesoscale (i.e., cloud system area $>$ $2000 \mathrm{~km}^{2}$ ). By simulating a real MJO event, we test the result from highly idealized RCE model simulations that surface fluxes are perhaps important or at least favorable for convective organization. The precipitationLHFLX relationship will be evaluated across various MJO regimes, since previous studies found that surface flux enhancements by MCSs depend on background winds (Esbensen and McPhaden 1996; Tompkins 2001; Wu and Guimond 2006; Chen et al. 2016).

The following section describes the CRM used in this study, the simulations, and the observational dataset used. Section 3 establishes model fidelity of the November MJO event relative to observations. Section 4 describes the control simulation's cluster characteristics including size distribution, day of occurrence, and their precipitation-LHFLX relationship during different MJO regimes, while section 5 compares the convective cluster characteristics from the control simulations with the sensitivity simulations. Section 6 compares convective organization in the control and sensitivity experiments to assess the importance of LHFLX feedbacks for convective organization. Finally, section 7 provides a discussion of our results, while section 8 summarizes the paper.

\section{Model and data description}

\section{a. Model description}

CRM simulations were completed using the Regional Atmospheric Modeling System (RAMS; Cotton et al. 2003; Saleeby and van den Heever 2013), version 6.14. RAMS is a fully compressible, nonhydrostatic model with two-moment bulk microphysics that predicts mixing ratio and number concentration for eight hydrometeor classes: cloud droplets, drizzle, rain, pristine ice, snow, aggregates, graupel, and hail (Walko et al. 1995; Meyers et al. 1997; Saleeby and Cotton 2004; Saleeby and van den Heever 2013). The Harrington (1997) radiation scheme is fully interactive with the microphysics and surface schemes. The Land Ecosystem-Atmosphere Feedback model, version 3 (LEAF-3), submodel within RAMS is used to represent surface-atmosphere heat and moisture exchange (Walko et al. 2000).

The RAMS simulations were approximately centered over the DYNAMO northern sounding array (NSA; Fig. 1). Simulations were run at two resolutions. A $1.5-\mathrm{km}$ horizontal simulation was conducted with interactive LHFLXs to evaluate the convective-scale relationship of MJO precipitation and LHFLXs. This $1.5-\mathrm{km}$-resolution simulation is $825 \mathrm{~km} \times 825 \mathrm{~km}$ (black square in Fig. 1). Another set of simulations was run at a degraded horizontal resolution of $4 \mathrm{~km}$ with a slightly smaller domain size of $800 \mathrm{~km} \times 800 \mathrm{~km}$ (Fig. 1, dashed red square). Using the 4-km-resolution setup, we ran two simulations with interactive LHFLXs (i.e., control simulations) and three sensitivity simulations with homogenized LHFLXs (detailed below) to test the importance of temporal and spatial LHFLX variability to MJO convection. Details of the model setup for each simulation are given in Table 1 and discussed below. Two control simulations were run to help determine if differences between the control and sensitivity simulations are greater than the differences caused by varying the initial condition. Results from the 4-km control simulations were similar to the $1.5-\mathrm{km}$ simulation (shown below). Taking this into account, as well as the computational expense associated with the $1.5-\mathrm{km}$-domain 


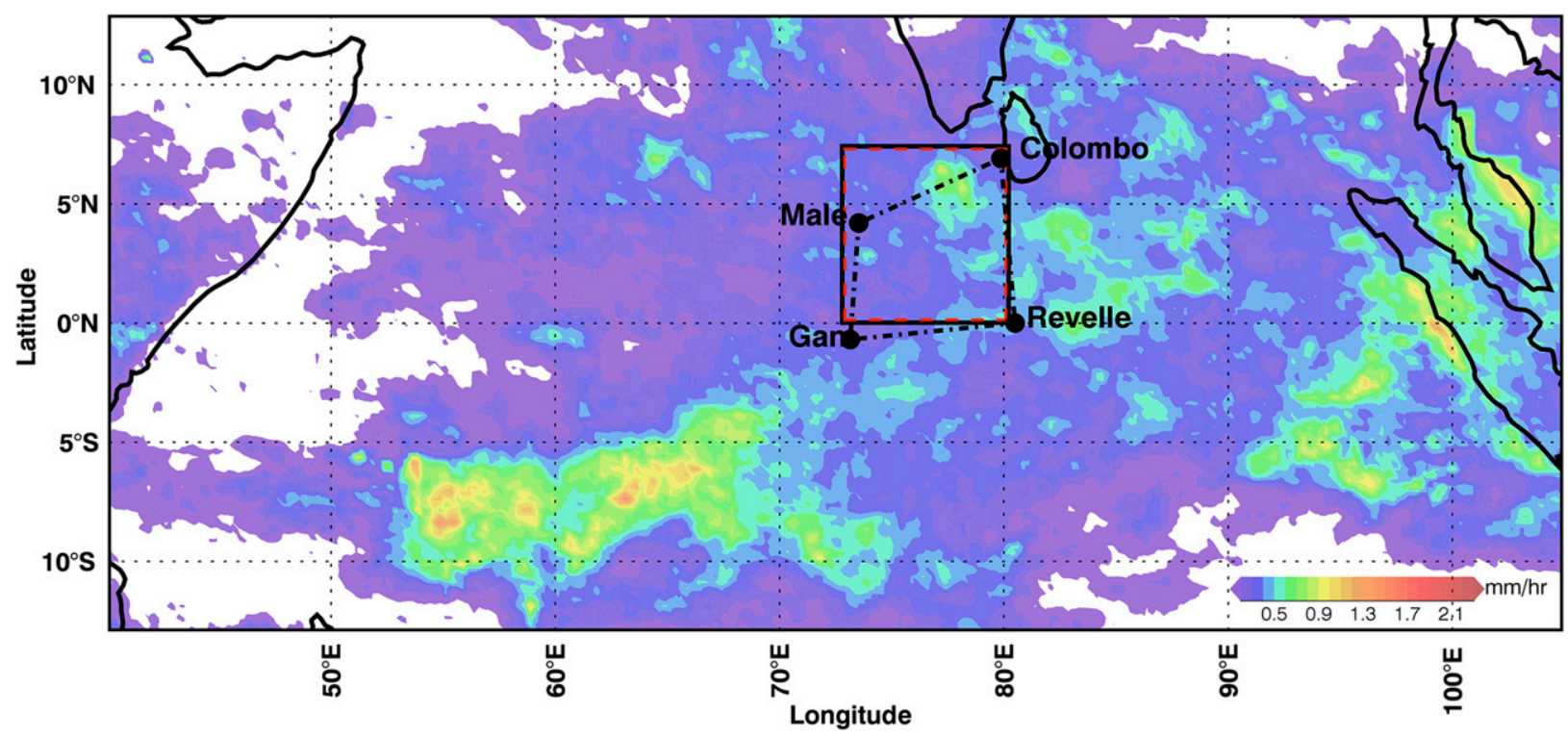

FIG. 1. The 1.5-km-resolution model domain is the solid black square, and the 4-km-resolution domain is the red dashed square. The dashed-dotted lines enclose the DYNAMO northern sounding array, with each sounding location labeled by the black circles. TRMM $3 \mathrm{~B} 42$ precipitation (colors; $\mathrm{mm} \mathrm{h}^{-1}$ ) is shown in the background averaged over the MJO event from 3 to 30 Nov.

simulations, the 4-km-domain setup was utilized in order to conduct more sensitivity simulations.

For all model domain setups, the vertical discretization consists of 65 stretched vertical levels up to $25.8 \mathrm{~km}$. Twelve levels are below $1 \mathrm{~km}$, and the highest levels are separated by $750 \mathrm{~m}$. The model time step is $5 \mathrm{~s}$ for the $1.5-\mathrm{km}$-domain setup and $10 \mathrm{~s}$ for the $4-\mathrm{km}$-domain setup. Although the Maldivian islands are contained within the domain, the simulations were run as ocean only using weekly (8 day) observed Moderate Resolution Imaging Spectroradiometer (MODIS) SSTs (Esaias et al. 1998). SSTs were therefore updated every 8 days. Between the 8-day MODIS SST updates, SSTs were linearly interpolated between the previous and next MODIS SST files.

The control simulations were initialized using $0.25^{\circ} \times$ $0.25^{\circ}$ European Centre for Medium-Range Weather Forecasts (ECMWF) interim reanalysis (ERA-Interim, hereafter ERA-I; Dee et al. 2011) regridded to the model grid. The $1.5-\mathrm{km}$ control simulation and one $4-\mathrm{km}$ control simulation were initialized on 0000 UTC 31 October 2011 and are referred to as " $1.5 \mathrm{Ctrl} 0$ " and "4Ctrl0,"respectively (Table 1). For these two simulations, domainwide nudging of horizontal winds, temperature, water vapor mixing ratio, and pressure (Exner function) was applied for the first day with a 4-h nudging time scale using the 6-hourly ECMWF reanalysis. The other 4-km control simulation was initialized on 1200 UTC 30 October 2011 and run with $36 \mathrm{~h}$ of domainwide nudging to ERA-I. This second $4-\mathrm{km}$ control simulation is referred to as "4Ctrl12" (Table 1). For all of the control simulations, the time period with domainwide nudging is considered model spinup and not included in analysis. Starting on 0000 UTC 1 November (i.e., after domainwide nudging has ceased in all control simulations), lateral boundary nudging was applied to the seven outermost grid points with a 30-min time scale. No other large-scale forcing was utilized. The lateral boundary-nudging scheme follows

TABLE 1. Simulation details, including experiment name, resolution, initialization time, length domainwide nudging was applied, and how the LHFLXs were applied. In the experiment name column, Uni is short for uniform and LH stands for latent heat fluxes.

\begin{tabular}{lclcr}
\hline \hline Experiment name & Resolution $(\mathrm{km})$ & Initialization time & Domainwide nudging $(\mathrm{h})$ & LHFLX treatment \\
\hline 1.5Ctrl0 & 1.5 & 0000 UTC 31 Oct & 24 & Interactive \\
4Ctr10 & 4 & 0000 UTC 31 Oct & 24 & Interactive \\
UniLH0a & 4 & 0000 UTC 2 Nov & - & Uniform from 4Ctrl0 \\
UniLH12 & 4 & 1200 UTC 2 Nov & 36 & Uniform from 4Ctrl0 \\
4Ctrl12 & 4 & 1200 UTC 30 Oct & - & Interactive \\
UniLH0b & 4 & 0000 UTC 2 Nov & Uniform from 4Ctrl12 \\
\hline
\end{tabular}




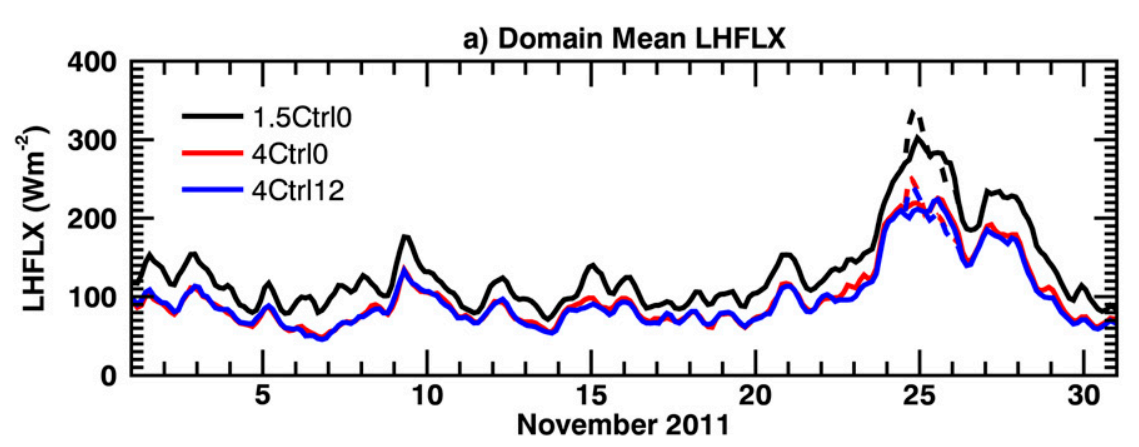

b) Domain Mean Precipitation

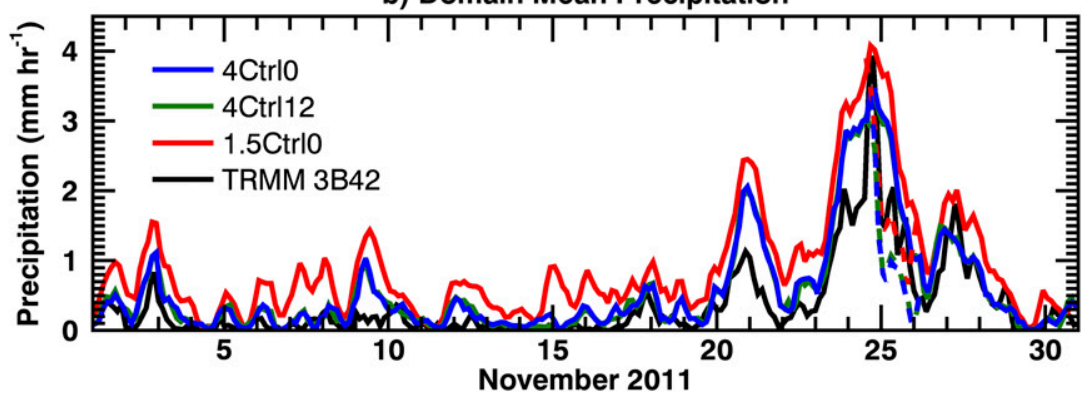

FIG. 2. (a) The 3-hourly averaged model domain-mean LHFLX for the $1.5 \mathrm{Ctrl0}$ (black), 4Ctrl0 (red), and 4Ctrl12 (blue) simulations. (b) The 3-hourly averaged model domain-mean surface precipitation for TRMM 3B42 (black) and RAMS 1.5Ctrl0 (red), 4Ctrl0 (blue), and 4Ctrl12 (green) simulations. The dashed line segments indicate how the removal of TC 5A affects domain-mean LHFLX and precipitation.

Davies (1976), in which the nudging time scale increases parabolically from the user-defined time scale at the boundary to infinity at the interior grid point of the relaxation region (i.e., the seventh innermost grid cell from the boundary in our setup). Nudging at the lateral boundaries to observations ensures that both the control and sensitivity simulations accurately capture the overall evolution of the November MJO event while allowing individual convective elements to evolve freely in the domain interior, ensuring explicit examination of how the wind-flux feedback alters convective organization. Variables discussed in sections 3-5 were output every $20 \mathrm{~min}$.

For the control simulations, the fluxes were calculated at each time step using the surface bulk aerodynamic formula. The two 4-km simulations using interactive surface fluxes are compared to three 4-km sensitivity simulations with spatially homogenized LHFLXs that evolve in time following the control simulations' domain-mean LHFLXs (Table 1). For each 20-min output time from a 4-km control simulation, LHFLXs were domain averaged and then applied homogeneously across all grid points in the sensitivity simulations. This allowed the domain-mean evolution of LHFLXs to remain the same as the control simulations while spatially homogenizing the fluxes at each time step to determine the impact of local flux variability on convective organization. The three sensitivity experiments differ in what control simulation they were branched from and when they were initialized (Table 1). We ran three sensitivity simulations to test the robustness of our results to different initial conditions. Figure 2a shows the domainmean LHFLXs for each of the control simulations. As explained above, the sensitivity simulations' domainmean LHFLXs evolved exactly as their parent control simulation domain-mean LHFLXs. The sensitivity simulations had homogenized LHFLXs updated every 20 min based on their control simulations' domain-mean LHFLXs (see Table 1).

\section{b. Observational data}

The TRMM 3B42, version 7, precipitation product (Huffman and Bolvin 2014) is used to validate model precipitation. TRMM 3B42 provides 3-hourly $0.25^{\circ} \times$ $0.25^{\circ}$ estimates of surface precipitation in the tropics and subtropics $\left(50^{\circ} \mathrm{S}-50^{\circ} \mathrm{N}\right)$ during the TRMM satellite era (January 1998-April 2015; Huffman et al. 2007).

The gridded sounding analysis described in Johnson and Ciesielski (2013) and Ciesielski et al. (2014) is used for comparison of DYNAMO observations of dynamic and thermodynamic variables to analogous model output. The gridded sounding analysis includes horizontal 
and meridional winds, pressure, temperature, geopotential height, and water vapor mixing ratio at 3 -hourly $1^{\circ} \times 1^{\circ}$ horizontal resolution and 25 -hPa vertical resolution from 1000 to $50 \mathrm{hPa}$ from 1 October to 31 December 2011.

\section{Model fidelity}

Figure 2 compares domain-averaged surface precipitation from the $1.5 \mathrm{Ctrl}, 4 \mathrm{Ctrl0}$, and $4 \mathrm{Ctrl12}$ simulations with TRMM 3B42 precipitation. The general pattern of precipitation is well captured by RAMS at both horizontal grid resolutions. However, the model generally produces heavier domain-averaged precipitation than TRMM 3B42, with the precipitation from the 4Ctrl0 and 4Ctrl12 simulations frequently closer to TRMM 3B42 precipitation than the precipitation from the $1.5 \mathrm{Ctrl0}$ simulation. It should be noted that the TRMM 3B42 detection limit is $17 \mathrm{dBZ}$ and hence may be missing light precipitation, therefore potentially underestimating satellite-estimated total precipitation (e.g., Huffman et al. 2007) and thereby making model-observation differences appear larger than they are. Also, the boundary forcing provided by ECMWF reanalysis may be inconsistent with the TRMM precipitation fields because of reanalysis model errors and other factors. The ECMWF reanalysis product is the result of data assimilation and may have a strong dependence on ECMWF model parameterizations in data-sparse regions. Since the dynamical model used in generating the reanalysis product is not perfect, the ECMWF fields we use to force RAMS will likely deviate somewhat from the real world.

Figure 3 shows time-longitude diagrams of surface precipitation from the $1.5 \mathrm{Ctrl0}$ and $4 \mathrm{Ctrl0}$ simulations and TRMM 3B42. Note that a different color scale is used for TRMM 3B42 (Fig. 3b) precipitation versus all other panels in Fig. 3. Precipitation fields were averaged in latitude across the domain. While both horizontal grid resolutions of RAMS appear to overestimate surface precipitation, they accurately capture the timing and eastward propagation of the MJO convective packet from 20 to 28 November (Figs. 3a,d vs Fig. 3b). Similar to Fig. 2, the $1.5 \mathrm{Ctrl0}$ simulation tends to have stronger precipitation than the 4-km simulation. Embedded within the MJO convective envelope is a westwardpropagating feature in both model grid resolution control simulations and a near-stationary feature in the observations on 24-25 November. These features likely represent the combination of a northwestward-moving tropical depression that moved through the NSA and became Tropical Cyclone (TC) 5A on 26 November and a westward-propagating equatorial Rossby wave that moved through the domain near the end of November (Gottschalck et al. 2013). Loops of the $1.5 \mathrm{Ctr} 10$ surface precipitation show a circulation associated with a tropical cyclone starting on 25 November in the northeast quadrant of the domain, moving northnorthwest and developing a well-defined center near the end of 25 November (supplementary movie).

Figure 4 compares the daily domain averages of specific humidity anomalies and zonal wind at all heights for the NSA gridded sounding analysis, ERA-I, and the 1.5Ctrl0 and 4Ctrl0 simulations. The NSA gridded analysis domain includes the area enclosed by the four sounding locations in Fig. 1. Daily specific humidity anomalies were computed relative to their respective modeled or observational-analysis monthly mean value at each height. The $1.5 \mathrm{Ctrl0}$ and $4 \mathrm{Ctrl0}$ specific humidity and zonal wind compare well with both the NSA gridded analysis and ERA-I. The RAMS simulations, the NSA gridded analysis, and ERA-I all show anomalously moist conditions starting at low levels (i.e., centered at $1-2 \mathrm{~km}$ ) around 18 November that then build upward through 28 November. The $1.5 \mathrm{Ctrl0}$ specific humidity anomalies are weaker than the NSA gridded analysis and ERA-I (Fig. 4c). The 1.5Ctrl0 and 4Ctrl0 simulations capture the transition of zonal winds from easterlies overlying westerlies at the start of the month, as the October MJO decays, to deep easterlies through the middle of the month followed by strong easterlies overlying westerlies starting during November 23. At the end of the month, the $1.5 \mathrm{Ctrl0}$ and $4 \mathrm{Ctrl0}$ low-level westerlies are slightly stronger, while the easterlies above are slightly weaker than the NSA gridded analysis zonal winds (Fig. 4, right panels). However, overall, there is good agreement between the simulated and observed zonal winds.

\section{4. $1.5-\mathrm{km}$ control simulation cluster characteristics}

\section{a. Cluster identification}

To discern the LHFLX-precipitation relationship on convective scales within the MJO, simulated convective cloud clusters (hereafter referred to as clusters) were identified. Then, composites of simulated LHFLX and surface precipitation were made within $\pm 0.5^{\circ}$ latitude and longitude of the area-weighted center of the clusters for various lag times. Clusters were identified based on cloud-top brightness temperature $\left(T_{B}\right)$ and surface rain rate thresholds. Because a wide range of $T_{B}$ thresholds have been used to identify cloud clusters from infrared satellite observations [e.g., 267 to $188 \mathrm{~K}$ in Table 1 of Mapes and Houze (1993)], we decided to simply use the 80 th percentile of cold cloud tops from the simulations to determine our $T_{B}$ threshold. To ensure we were 

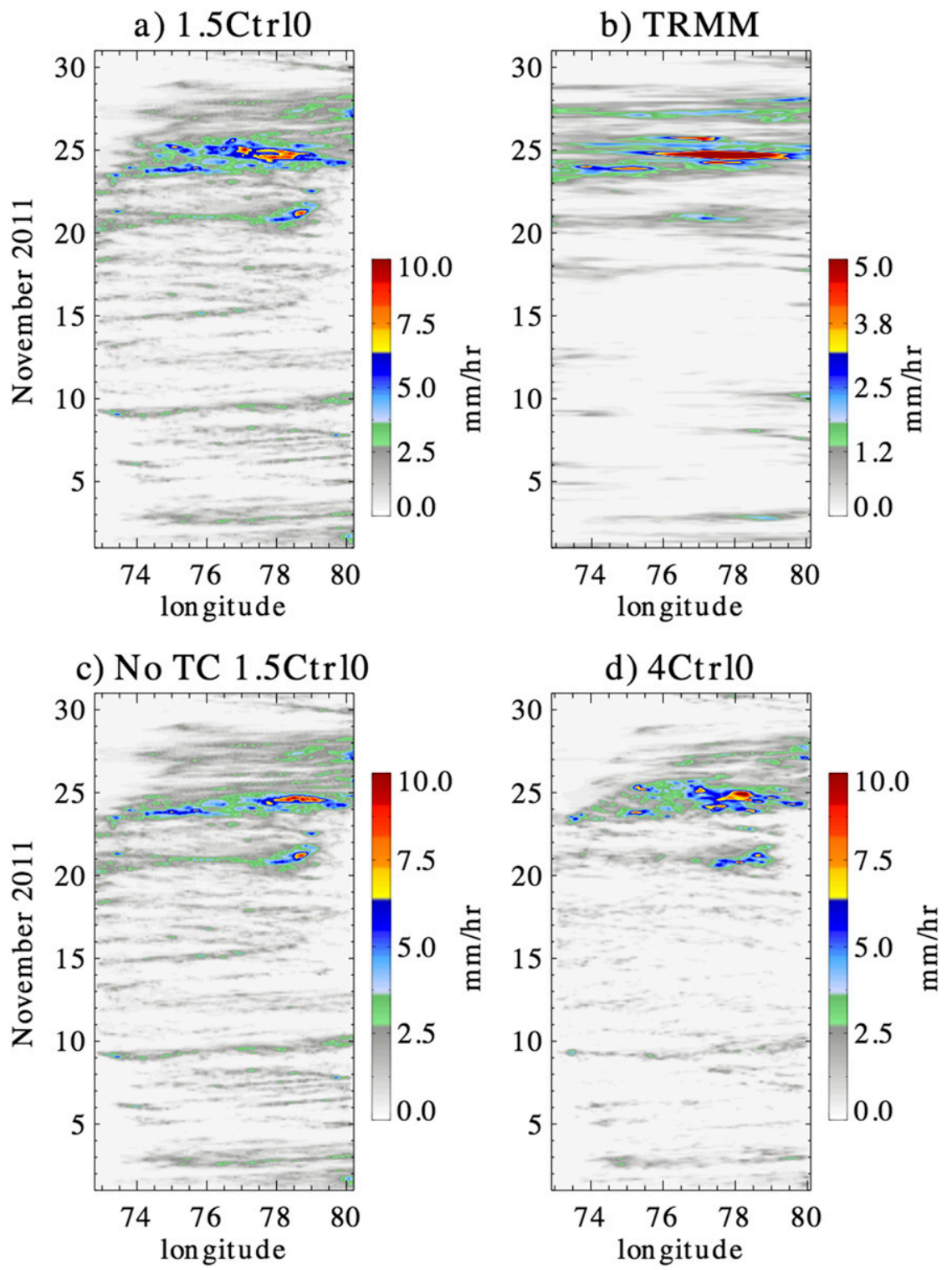

FIG. 3. Time-longitude diagrams of (a) RAMS-simulated surface precipitation for the 1.5Ctrl0 simulation and (b) TRMM 3B42 observations over the model domain. (c) As in (a), except TC 5A has been removed. (d) As in (a), but for the 4Ctrl0 simulation. Note the different surface precipitation range for $(b)$.

analyzing deep convective clouds that produced surface precipitation, we used the 90th percentile of surface rain rate as our precipitation threshold. The percentiles were determined from cumulative probability distribution functions (PDFs) of each variable (not shown). Note, the cumulative PDF used to determine the 90th percentile of precipitation included nonraining or $0 \mathrm{~mm} \mathrm{~h}^{-1}$ points. Using the 90th-percentile threshold for surface rain rate and the 80th-percentile threshold for cold cloud tops, a cluster was identified for the $1.5 \mathrm{Ctrl} 0$ simulation as a contiguous region of grid points with $T_{B}<203 \mathrm{~K}$ and surface rain rate $>0.91 \mathrm{~mm} \mathrm{~h}^{-1}$. For the $4 \mathrm{Ctrl} 0$, the 80th-percentile $T_{B}$ threshold is $217 \mathrm{~K}$, and the 90thpercentile surface rain-rate threshold is $0.29 \mathrm{~mm} \mathrm{~h}^{-1}$. The $4 \mathrm{Ctrl} 12$ had the same 80 th-percentile $T_{B}$ threshold but a 90th-percentile precipitation threshold of $0.28 \mathrm{~mm} \mathrm{~h}^{-1}$. For all control simulations, the $T_{B}$ threshold falls within the range of $T_{B}$ thresholds discussed in Mapes and Houze (1993).

Grid points associated with the TC moving through the model domain between 24 and 26 November were subjectively excluded from analysis as we do not want 

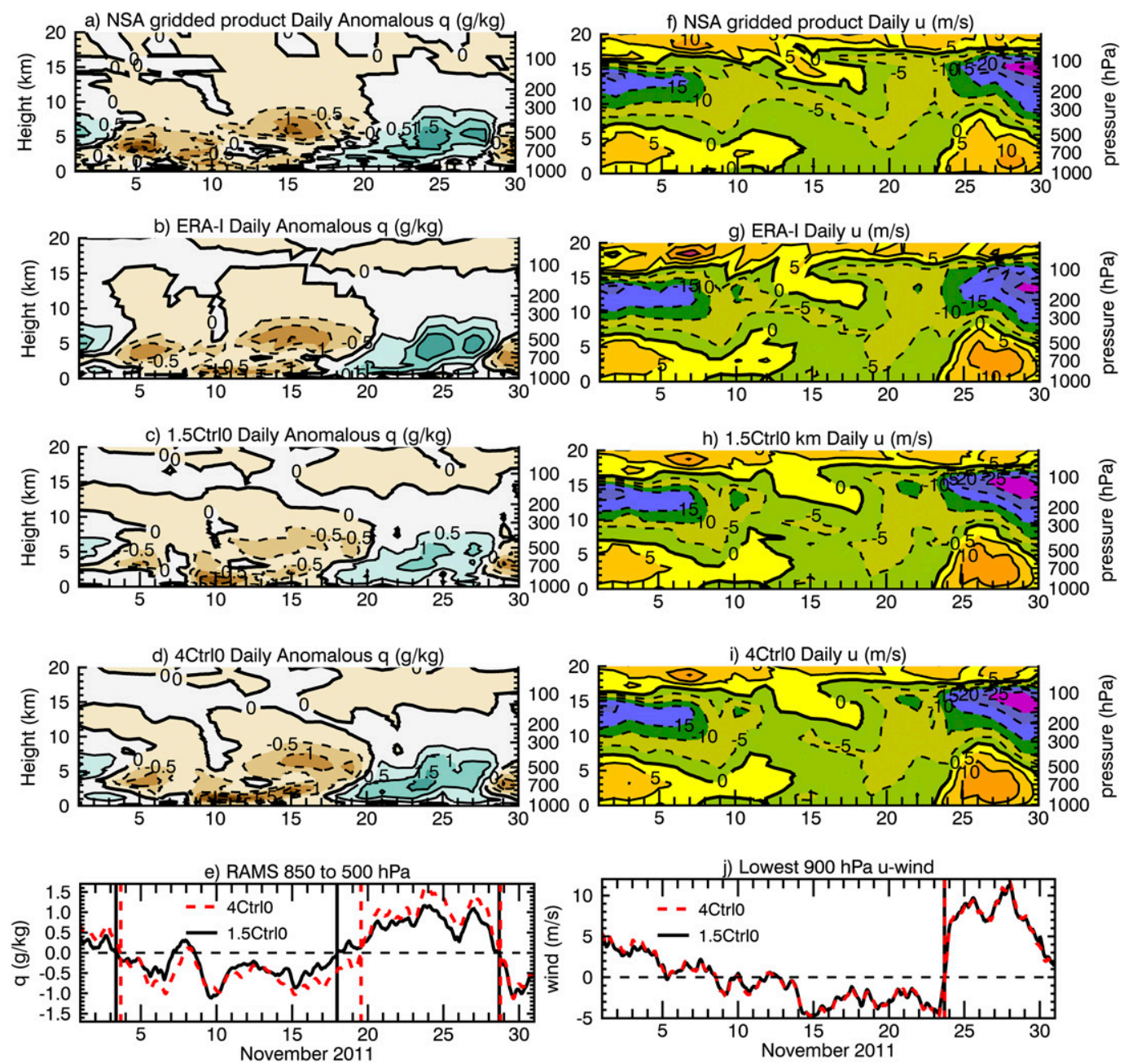

FIG. 4. Specific humidity anomalies from (a) the gridded observational product averaged over the NSA, (b) the ERA-I averaged over ERA-I points within the model domain, (c) the $1.5 \mathrm{Ctrl} 0$ simulation, and (d) the 4Ctrl0 simulation averaged over the model domain. Solid lines indicate positive anomalies, while dashed indicate negative anomalies. The thick black line is the zero contour. (e) The $1.5 \mathrm{Ctrl0}$ (black solid) and 4Ctrl0 simulation (red dashed) $q$ anomalies averaged from 850 to $500 \mathrm{hPa}$. The vertical lines near $3 \mathrm{Nov}$ and near 29 Nov indicate the start of the suppressed regime, while the vertical lines on $18 \mathrm{Nov}$ and between 19 and 20 Nov indicate the start of the onset regime. (f)-(i) As in (a)-(d), but for zonal wind. (j) The 1.5Ctrl0 and 4Ctrl0 simulation lowest 900-hPa averaged zonal wind. The vertical lines in (j) indicate the start of the WWB regime.

to mix TC-LHFLX feedbacks with the LHFLX feedbacks for ordinary (i.e., non-TC) convection. Based on subjective identification of TC circulation and convection, model output north of $3^{\circ} \mathrm{N}$ was excluded from 1440 UTC 24 November to 0700 UTC 25 November, while from 0720 UTC 25 November to 0440 UTC 26 November, model output north of $4^{\circ} \mathrm{N}$ was excluded (supplementary movie). The dashed lines in Fig. $2 b$ and Fig. $3 c$ demonstrate how the removal of the TC affected precipitation. Excluding TC $5 \mathrm{~A}$ removed the westward-propagating feature in the time-longitude diagram from 25 to 26 November (Figs. 3a,c). The dashed lines in Fig. 2a indicate how removal of the TC affected domain-mean LHFLX for the $1.5 \mathrm{Ctrl} 0$ simulation and the two $4-\mathrm{km}$ control simulations.

\section{b. Cluster classification}

Clusters were stratified into MJO regimes to determine if and how the LHFLX-precipitation relationship changes across MJO thermodynamic and dynamic background states. Clusters were also stratified by size, since the small clusters dominated the cluster count and therefore skewed composites over all sizes to only represent the small-sized clusters. Stratifying clusters by size is also important to evaluate if and how the precipitation- 


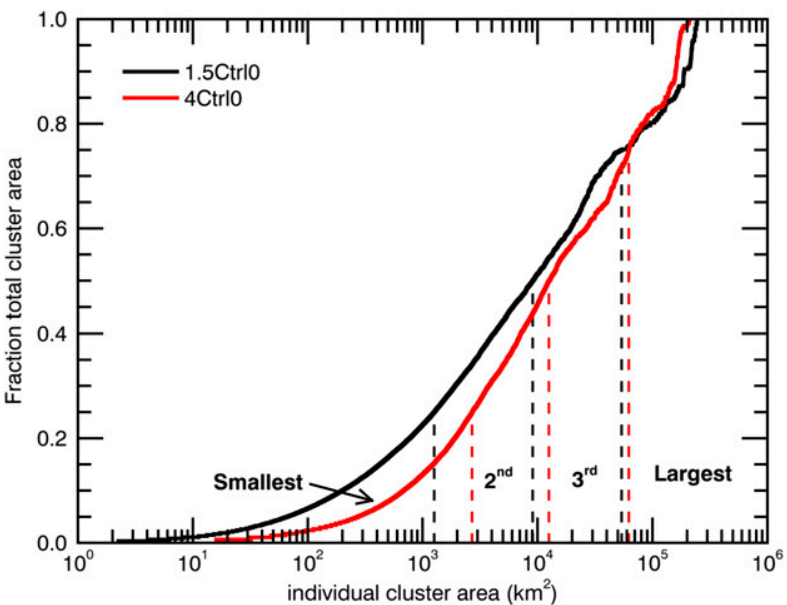

FIG. 5. Cumulative histogram of cluster area for the $1.5 \mathrm{Ctrl0}$ (black lines) and 4Ctrl0 simulations (red lines) broken into quartiles (dashed vertical lines). Clusters falling within each quartile make up $25 \%$ of the total area of all the clusters. For example, clusters within the smallest-size quartile of the $1.5-\mathrm{km}$ simulation (i.e., smaller than $1259.25 \mathrm{~km}^{2}$ ) make up $25 \%$ of all cluster area. Each quartile is labeled according to how it is referenced in the text.

LHFLX relationship changes across convective scales. MJO regimes were determined by shifts in domain-mean low-level free-troposphere (i.e., $850-500 \mathrm{hPa}$ ) specific humidity anomalies and low-level (i.e., below $900 \mathrm{hPa}$ ) zonal wind (Figs. 4e,j). Days in November were classified into three regimes: suppressed, onset, and westerly wind burst (WWB). The suppressed regime occurs when lowlevel free-tropospheric moisture is anomalously dry, which is from 0840 UTC 3 November to 2320 UTC 17 November and then again from 1640 UTC 28 November until the end of the month for the 1.5Ctrl0 simulation (Fig. 4e, black vertical lines). For the 4Ctrl0, the suppressed regime goes from 1600 UTC 3 November to 1320 UTC 19 November and then again from 1820 UTC 28 November until the end of the month (Fig. 4e, red dashed lines). Onset occurs for the $1.5 \mathrm{Ctrl0}$ simulation on 2340 UTC 17 November, when low-level freetropospheric moisture anomalies switch to positive, and lasts until 1600 UTC 23 November, when low-level winds become westerly (Fig. 4j). Onset for the 4Ctrl0 simulation begins on 1340 UTC 19 November. For both the $1.5 \mathrm{Ctrl} 1$ and 4Ctrl0 simulations, the onset day is close to the DYNAMO sounding-based onset day of 17 November (Ruppert and Johnson 2015). WWB days are from 1620 UTC 23 November to 1620 UTC 28 November for the 1.5Ctrl0 simulation, while 1640 UTC 23 November to 1800 UTC 28 November 18 are the WWB days for the 4Ctrl0 simulation, because of the strong westerly winds at low levels (Fig. 4j). The regime transitions for the 4Ctrl12 simulation are within an hour of the 4Ctrl0 simulation, while all three sensitivity simulations' (see Table 1) regimes vary from the 4 Ctrl12 regimes by $2 \mathrm{~h} 40 \mathrm{~min}$ or less. Because of the similarity of regime timing among all of the 4-km simulations, we simply applied the 4Ctrl0 simulation regime distinction times to all the $4-\mathrm{km}$ simulations.

Clusters were also grouped into quartiles based on the total area of all clusters (Fig. 5). For example, in the $1.5 \mathrm{Ctrl} 0$ simulation, $25 \%$ of the total cluster area is accounted for by clusters smaller than $1259.25 \mathrm{~km}^{2}$ (Fig. 5 , leftmost black dashed line), while another $25 \%$ of the total area was contained in clusters larger than $53959.25 \mathrm{~km}^{2}$ (Fig. 5, rightmost black dashed line). Clusters falling in the smallest-size quartile of the $1.5 \mathrm{Ctrl0}$ simulation (i.e., smaller than $1259.25 \mathrm{~km}^{2}$ ) can be thought of as submesoscale given the Yuan and Houze (2010) MCS definition (i.e., area $<2000 \mathrm{~km}^{2}$ ). Table 2 shows the number of clusters from the $1.5 \mathrm{Ctrl} 0$ simulation for each $\mathrm{MJO}$ regime and size quartile. Establishing size quartiles based on cumulative cluster area resulted in a similar number of clusters in each $\mathrm{MJO}$ regime for a given size quartile.

Figure 6 shows the distribution of clusters by day for each size quartile. The red histograms indicate the percent of the total number of clusters that occur on each day. The sum of the red histograms over all size quartiles and days is $100 \%$. Though there are quantitative differences between the $1.5 \mathrm{Ctrl} 10$ and $4 \mathrm{Ctrl} 0$ simulations, the two simulations are qualitatively similar in the following ways. Generally, clusters contained within an individual-size quartile occurred in all three MJO regimes (Fig. 6, red lines). The exception is the quartile containing the largest clusters. These largest-sized clusters occurred only during MJO onset and WWB regimes. Additionally, the red histograms in Fig. 6

TABLE 2. The left number in each bin is the number of clusters in each indicated MJO regime and cluster-size quartile. The right number in parentheses is the percent of clusters from each regime and size quartile that were used to make the $0.5^{\circ}$ composites for Figs. 7-12.

\begin{tabular}{lcccc}
\hline & Smallest & Second quartile & Third quartile & Largest \\
\hline Suppressed & $76501(85.8 \%)$ & $1371(91.2 \%)$ & $132(97.0 \%)$ & - \\
Onset & $83818(85.7 \%)$ & $1675(87.1 \%)$ & $284(99.3 \%)$ & $31(100 \%)$ \\
WWB & $97686(84.7 \%)$ & $1368(87.6 \%)$ & $255(93.3 \%)$ & $65(100 \%)$ \\
\hline
\end{tabular}



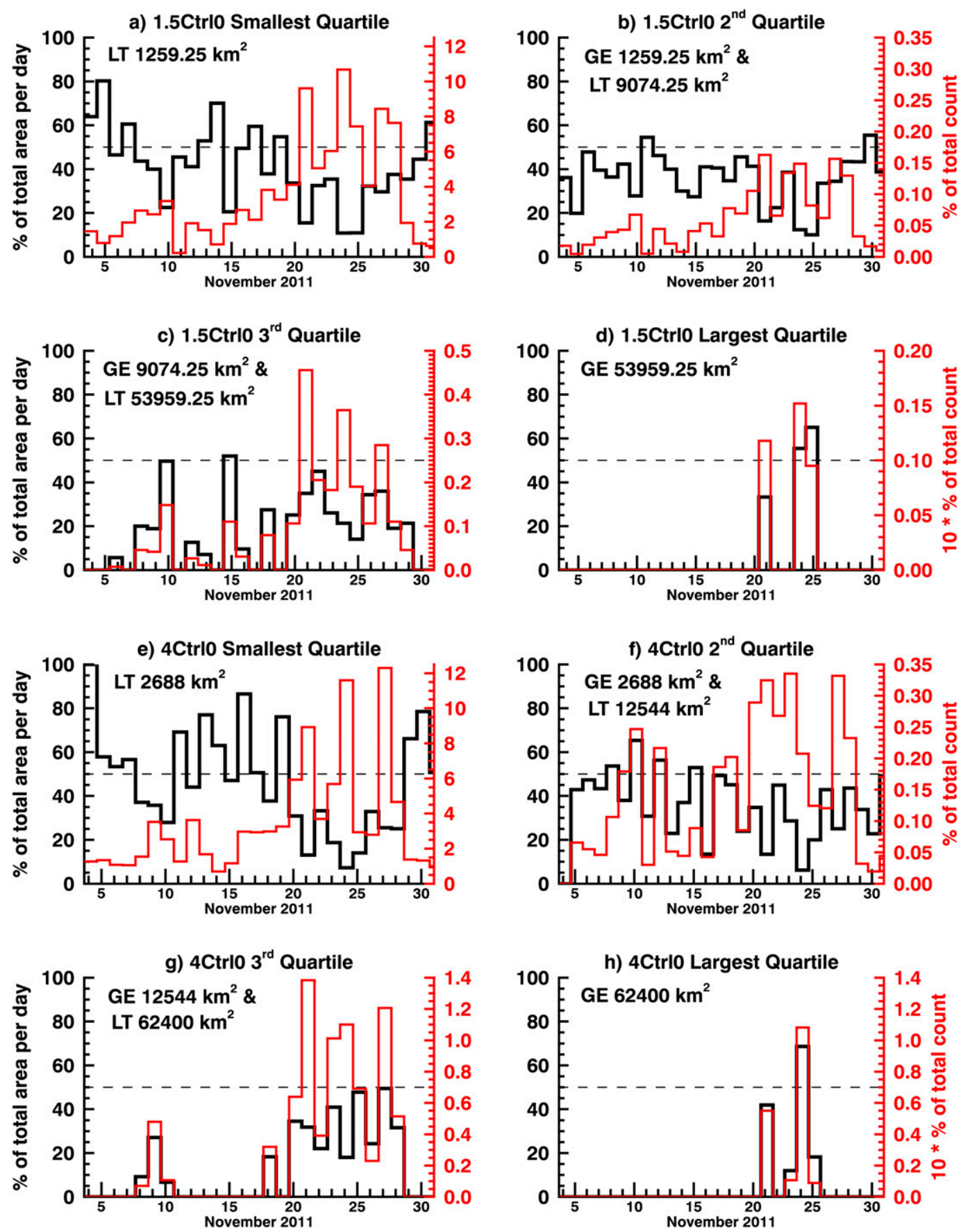

FIG. 6. Black histograms indicate the percent of the total cluster area per day that occurs in each indicated size quartile for the (a)-(d) 1.5Ctrl0 simulation and (e)-(h) 4Ctrl0 simulation. For each day, the sum of all four black size-quartile histograms is $100 \%$. Red histograms indicate the percent count of clusters that occur on each day for the indicated size quartile. The sum of all size quartiles and days for the red histograms equals $100 \%$. The clustersize thresholds used for each size quartile and simulation is indicated on individual panels: $\geq(\mathrm{GE})$ and $<(\mathrm{LT})$. Note that the right $y$ axis (i.e., red axis) varies across panels. The bin size for all histograms is 1 day.

show that the occurrence of clusters within the smallest-, second-, and third-size quartiles increased from suppressed to onset to WWB regime days, which is consistent with observations, namely, Riley et al. (2011), who showed that all cloud types increased during active MJO phases.

The black histograms in Fig. 6 show the percent contribution to total cluster area per day from clusters in 


\section{Suppressed Regime Smallest $25 \%$}
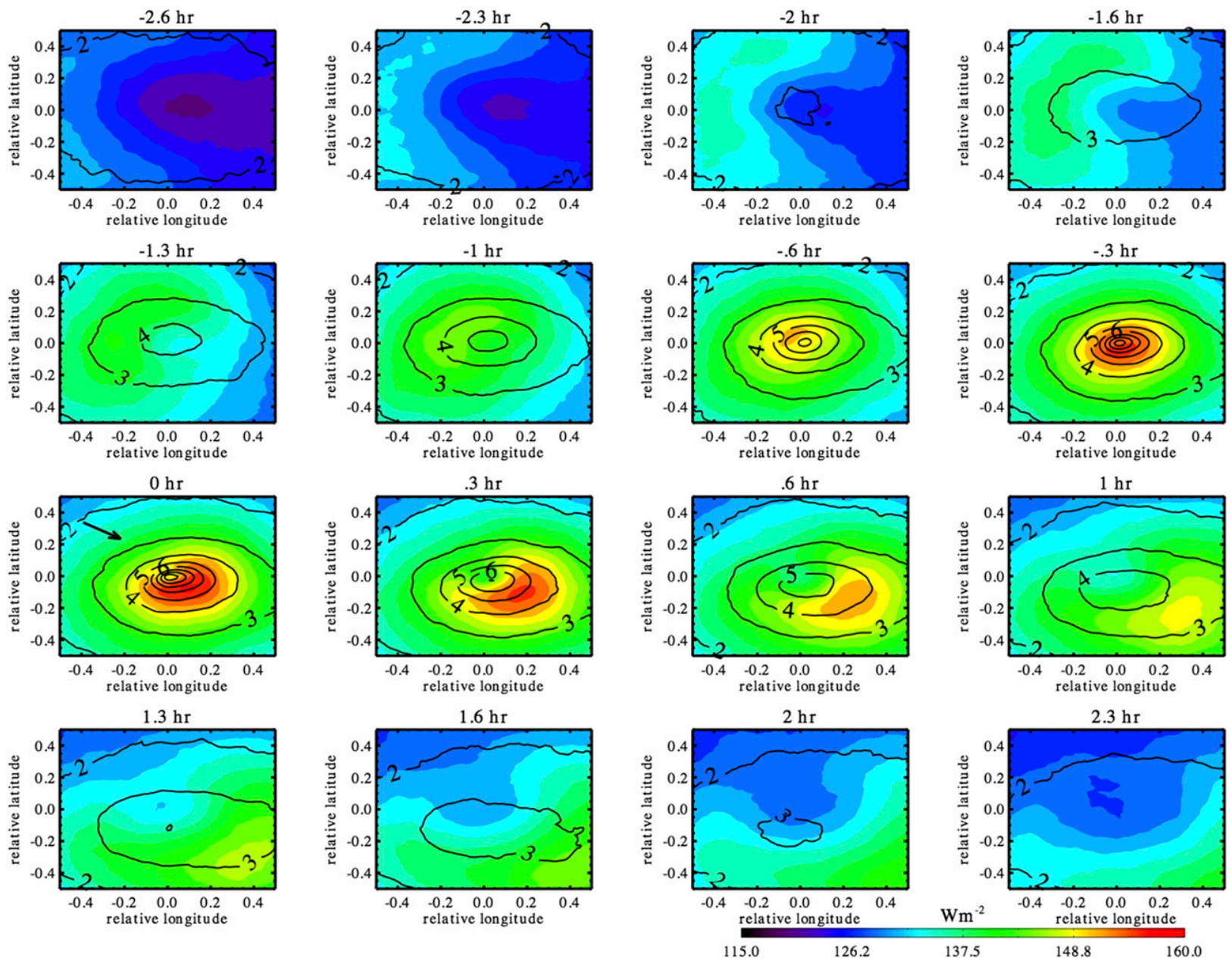

FIG. 7. Composites of LHFLX (color shading) and precipitation (black contours) surrounding $0.5^{\circ}$ latitude-longitude of clusters falling into the smallest-size quartile during the suppressed regime. Composites are from $2.6 \mathrm{~h}(2 \mathrm{~h} 40 \mathrm{~min})$ before the cluster is identified to $2.3 \mathrm{~h}(2 \mathrm{~h} 20 \mathrm{~min})$ after the cluster is identified, where $t=0$ is the time when the cluster is identified. The mean wind vector over the composite time and spatial scale for $4 \mathrm{~h}$ before and after cluster identification is overlaid on the $t=0$ panel. Its magnitude is $1.1 \mathrm{~m} \mathrm{~s}^{-1}$. The mean wind vector was insensitive to averaging winds $12 \mathrm{~h}$ before and after cluster identification. Precipitation (black) contours are every $1 \mathrm{~mm} \mathrm{~h}^{-1}$.

each size quartile. The sum of the black lines over all size quartiles is $100 \%$ for each day. Such a plot allows assessment of shifts in the fractional contribution of various-sized clusters as the MJO evolves. For both the $1.5 \mathrm{Ctrl} 0$ and $4 \mathrm{Ctrl} 0$ simulations, the smallest clusters (Figs. 6a,e) have their largest fractional contribution to daily total cluster area during the suppressed regime despite being most prevalent during the onset and WWB regime. This is consistent with Riley et al. (2011), who found CloudSat-observed narrow deep convective clouds had their largest fractional contribution to cloud cover during building and decaying MJO phases (their Fig. 5b). Clusters from the second and third cluster-size quartiles do not show a very distinct change in fractional contribution to total cluster area through the November MJO event except for clusters in the third-size quartile of the 4Ctrl0 simulation (Figs. 6b,c,f,g, black lines).

\section{c. Cluster composites}

Figures 7-12 show composites of LHFLX, surface precipitation, and lowest model level (i.e., $34.6 \mathrm{~m}$ above ground level) specific humidity $(q)$ and wind within $0.5^{\circ}$ latitude and longitude of a cluster's area-weighted center for clusters from the $1.5 \mathrm{Ctrl} 0$ simulation falling in the various-size quartiles and regimes for $2.6 \mathrm{~h}$ before the cluster was identified to $2.3 \mathrm{~h}$ after the cluster was identified. The compositing is done backward and forwards in time surrounding the clusters' area-weighted 


\section{Suppressed Regime Smallest 25\%}
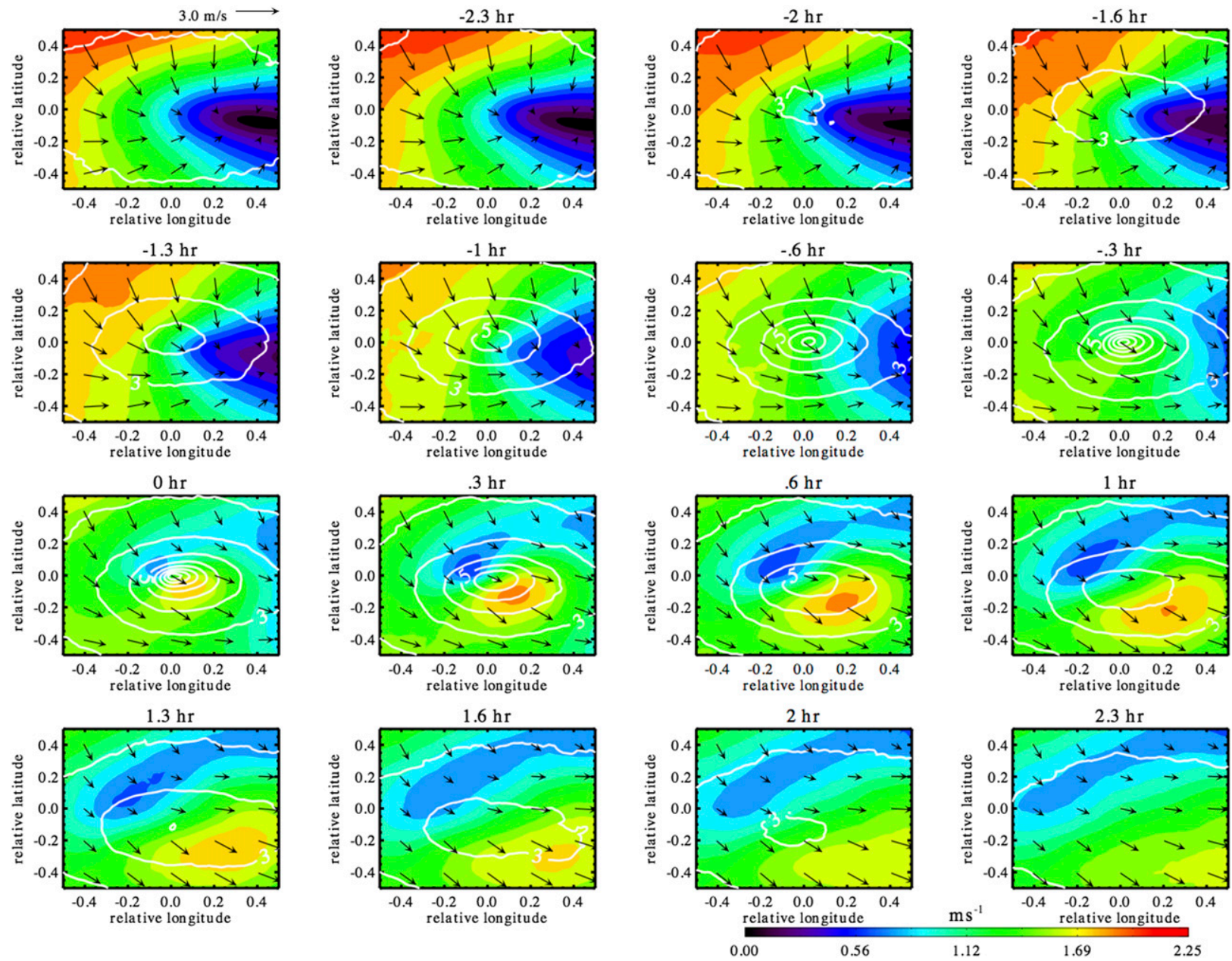

FIG. 8. Composites of wind speed (color shading), precipitation (white contours), and wind vectors surrounding $0.5^{\circ}$ latitude-longitude of clusters falling into the smallest-size quartile during the suppressed regime. Composites are from $2.6 \mathrm{~h}(2 \mathrm{~h} 40 \mathrm{~min})$ before the cluster is identified to $2.3 \mathrm{~h}(2 \mathrm{~h} 20 \mathrm{~min})$ after the cluster is identified, where $t=0$ is the time when the cluster is identified. The reference wind vector is given above the top-left panel. Precipitation (white) contours are every $1 \mathrm{~mm} \mathrm{~h}^{-1}$.

center at $t=0$ (i.e., the time the cluster is identified). The clusters are not tracked in time. Therefore, the composite does not follow an individual cluster's life cycle. Note, to be included in the composite, a cluster's areaweighted center had to be at least $0.5^{\circ}$ from the model domain boundary to ensure that each point within the composite contained the same amount of information. The percent of clusters included in the composites is shown in Table 2. By not tracking the clusters, the same cluster (in terms of life cycle evolution) may be counted multiple times in the composites. To ensure that the results were not skewed by our compositing method, we verified the results of the $1.5 \mathrm{Ctrl} 0$ composites with a different method that composited around only the "most mature" or coldest clusters relative to other clusters at the same time and for surrounding times.
First, we identified the cluster with the lowest $T_{B}$ at each time for each size quartile. Then, a time series of the $T_{B}$ for these mature clusters was made for each size quartile. Local minimums in the time series were then isolated to identify the most mature clusters as time progresses (i.e., the coldest cluster for times surrounding each time). Composites of LHFLX and precipitation were then made around these local (in time and space) mature clusters for each size quartile and $\mathrm{MJO}$ regime. This method likely ensures that clusters are not double counted because it would be highly unlikely for an individual cluster to go from mature (i.e., coldest $T_{B}$ ) to decaying (i.e., warmer $T_{B}$ ) then back to mature (i.e., to again be the coldest $T_{B}$ at a later time). The evolution of LHFLX and precipitation using this different compositing method (not shown) is qualitatively the same as the 


\section{Suppressed Regime Smallest $25 \%$}
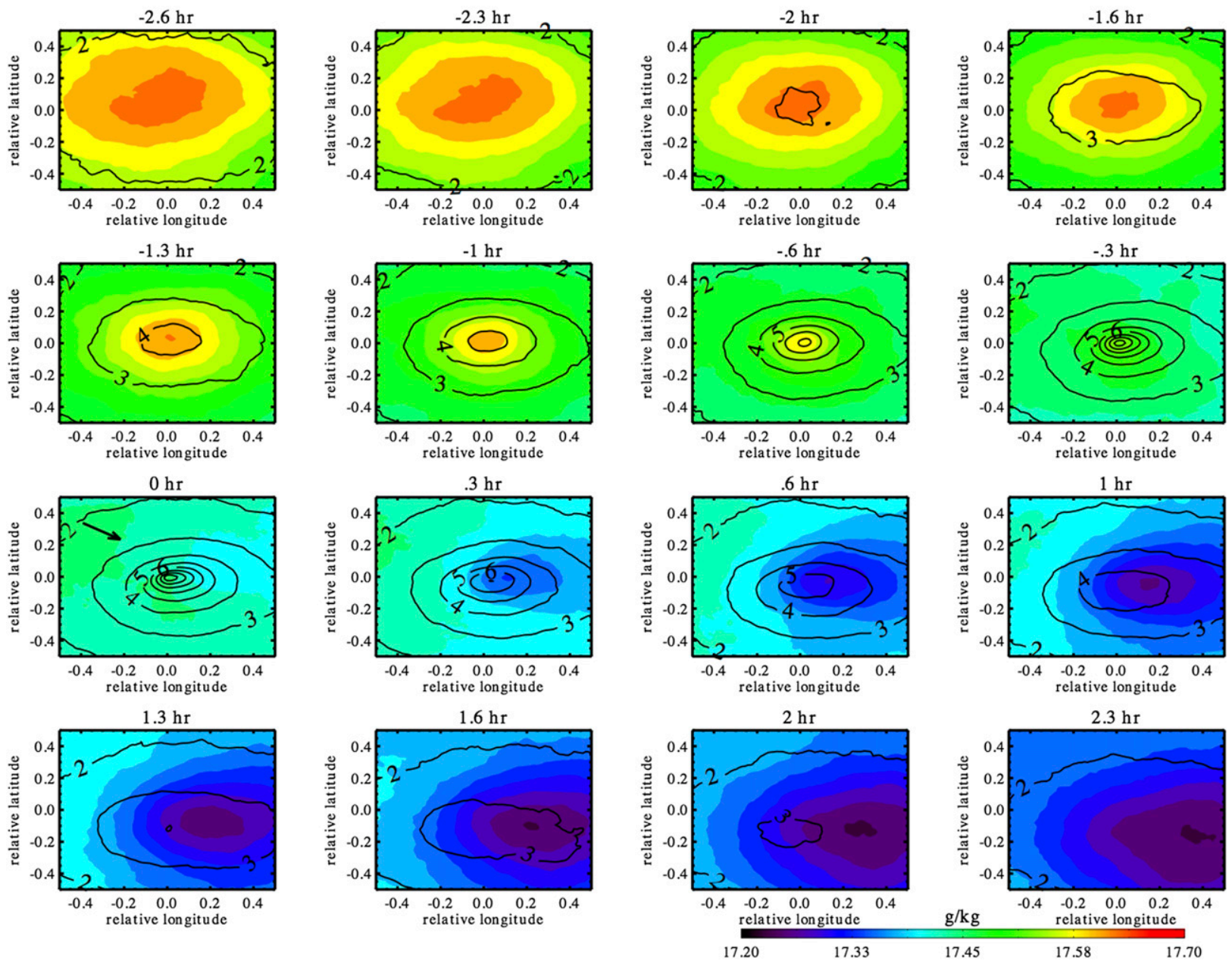

FIG. 9. As in Fig. 7, except the color shading is specific humidity.

evolution of LHFLX and precipitation shown below. Compositing around only the coldest or most mature clusters in local space and time severely limits the number of clusters in the composite, thus making the composites much noisier than the technique of compositing around all clusters for a given size quartile and MJO regime. Therefore, we show the results compositing around all clusters.

We look at composites of $q$ and wind speed since LHFLX is dependent on both variables:

$$
\mathrm{LH}=\rho L C_{H} V \Delta q,
$$

where $\rho$ is the density of near-surface air $\left(\mathrm{kg} \mathrm{m}^{-3}\right), L$ is the latent heat of vaporization $\left(\mathrm{J} \mathrm{kg}^{-1}\right), C_{H}$ is the exchange coefficient (dimensionless), $V$ is the wind speed $\left(\mathrm{m} \mathrm{s}^{-1}\right)$ and $\Delta q$ is the difference between saturation $q$ of SST and $q$ of near-surface air temperature $\left(\mathrm{kg} \mathrm{kg}^{-1}\right)$.
Composites were made for as many as $12 \mathrm{~h}$ before and after cluster identification for clusters in each size and regime category, but the 2.6-h-before and 2.3-h-after cluster identification time period sufficiently captures the evolution of the LHFLX-precipitation relationship on the convective scale while also reducing the number of panels shown. Panels progress in 20-min time increments, with $t=0$ the time when a cluster was identified. The composite area and temporal mean wind vector for $4 \mathrm{~h}$ before and after cluster identification is shown on the $t=0$ panel.

While Figs. 7-12 show composites from the $1.5 \mathrm{Ctr} 10$ simulation, the composites from both $4-\mathrm{km}$ control simulations have a qualitatively similar evolution in precipitation, LHFLX, and wind speed compared to the $1.5 \mathrm{Ctrl} 0$ composites. The main difference between the $4-\mathrm{km}$ and $1.5-\mathrm{km}$ control simulations is that the $4-\mathrm{km}$ composites have weaker precipitation, LHFLX, and wind 


\section{WWB Regime Smallest 25\%}
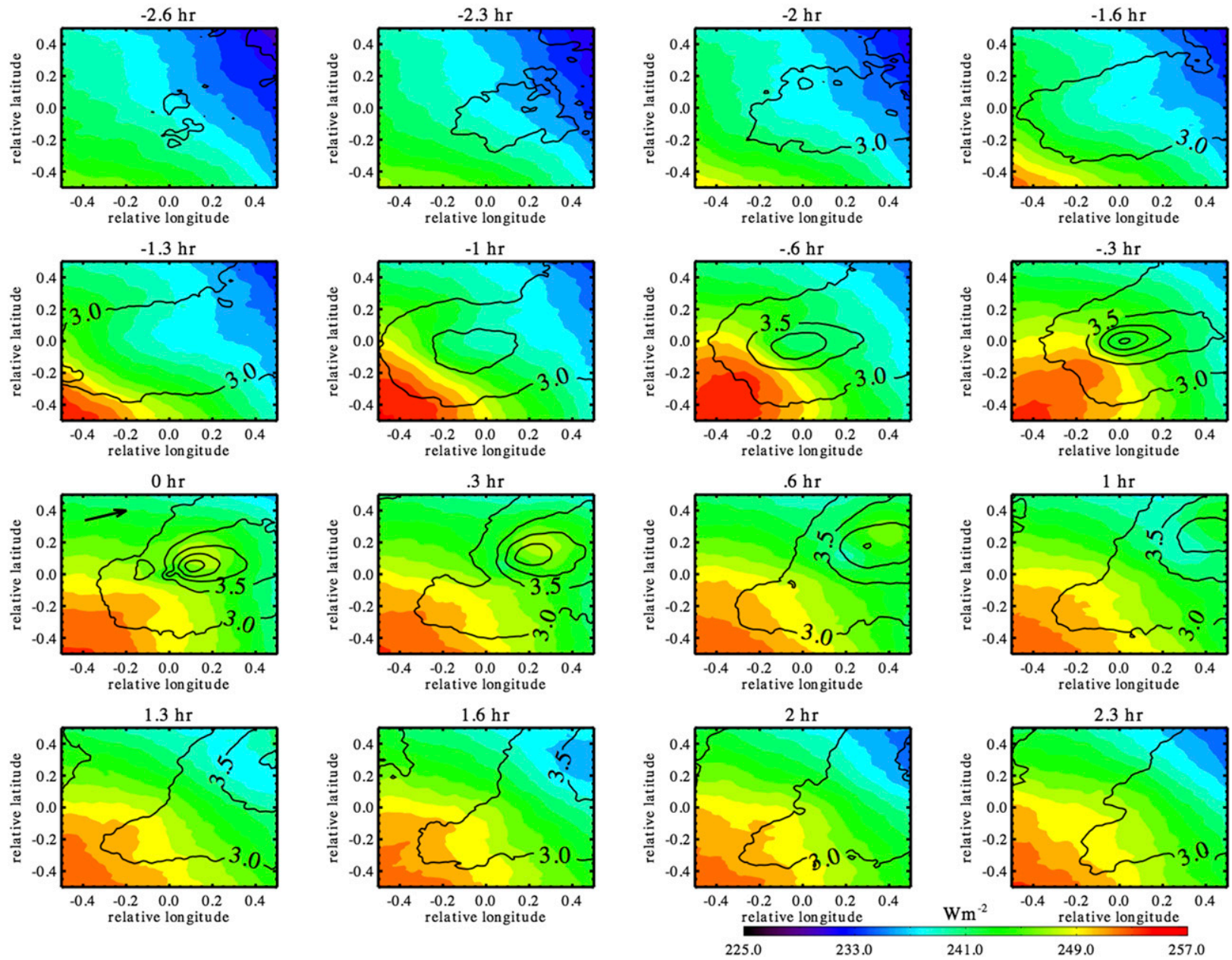

FIG. 10. As in Fig. 7, but for the WWB regime. Note that the LHFLX range is different than Fig. 7 and precipitation contours are every $0.5 \mathrm{~mm} \mathrm{~h}^{-1}$ instead of every $1 \mathrm{~mm} \mathrm{~h}^{-1}$. The magnitude of the mean wind vector is $7.7 \mathrm{~m} \mathrm{~s}^{-1}$.

speed values compared to the $1.5-\mathrm{km}$ simulation. Two supplementary figures are discussed below to prove the similarity between the two model grid resolutions.

\section{1) SMALlEST-SIZE QUARTILE ClUSTERS}

Figure 7 shows composites of LHFLX and precipitation for clusters in the smallest-size quartile (Fig. 5) during the suppressed regime of the 1.5Ctrl0 simulation. Before $t=0$, the largest LHFLXs generally occur upwind (relative to the mean vector) of the precipitation maximum. As $t=0$ is approached, the LHFLX and precipitation maxima increase and become coincident as the LHFLX maximum moves southeastward. On and after $t=0$, the maximum in LHFLXs moves downwind of the precipitation maximum, and both variables decrease in amplitude with time. At $t=0$ when precipitation is occurring at its highest rate, a local minimum in LHFLX develops underneath the precipitation maximum. As time progresses, this "notch" in lower LHFLXs expands and stays slightly upwind of the precipitation maximum. Supplementary Fig. S1 (online file JAS-D-16-0346s1) is the same as Fig. 7, but for the 4Ctrl0 simulation. The evolution of the precipitation and LHFLXs in the 4Ctrl0 simulation is qualitatively similar to the $1.5 \mathrm{Ctrl0}$ simulation shown in Fig. 7 . The precipitation in the $4 \mathrm{Ctrl0}$ simulation is weaker than the 1.5Ctrl0 simulation, which is similar to the results shown in Figs. 2 and 3. The composite LHFLX values are also weaker in the 4Ctrl0 simulation.

Composites of wind speed and wind vectors for clusters falling in the smallest-size quartile during the suppressed regime are similar in spatial pattern to those clusters' LHFLX composites (cf. Figs. 7 and 8), suggesting the LHFLXs are largely driven by wind speed 


\section{On set Regime $2^{\text {nd }}$ Size Quartile}
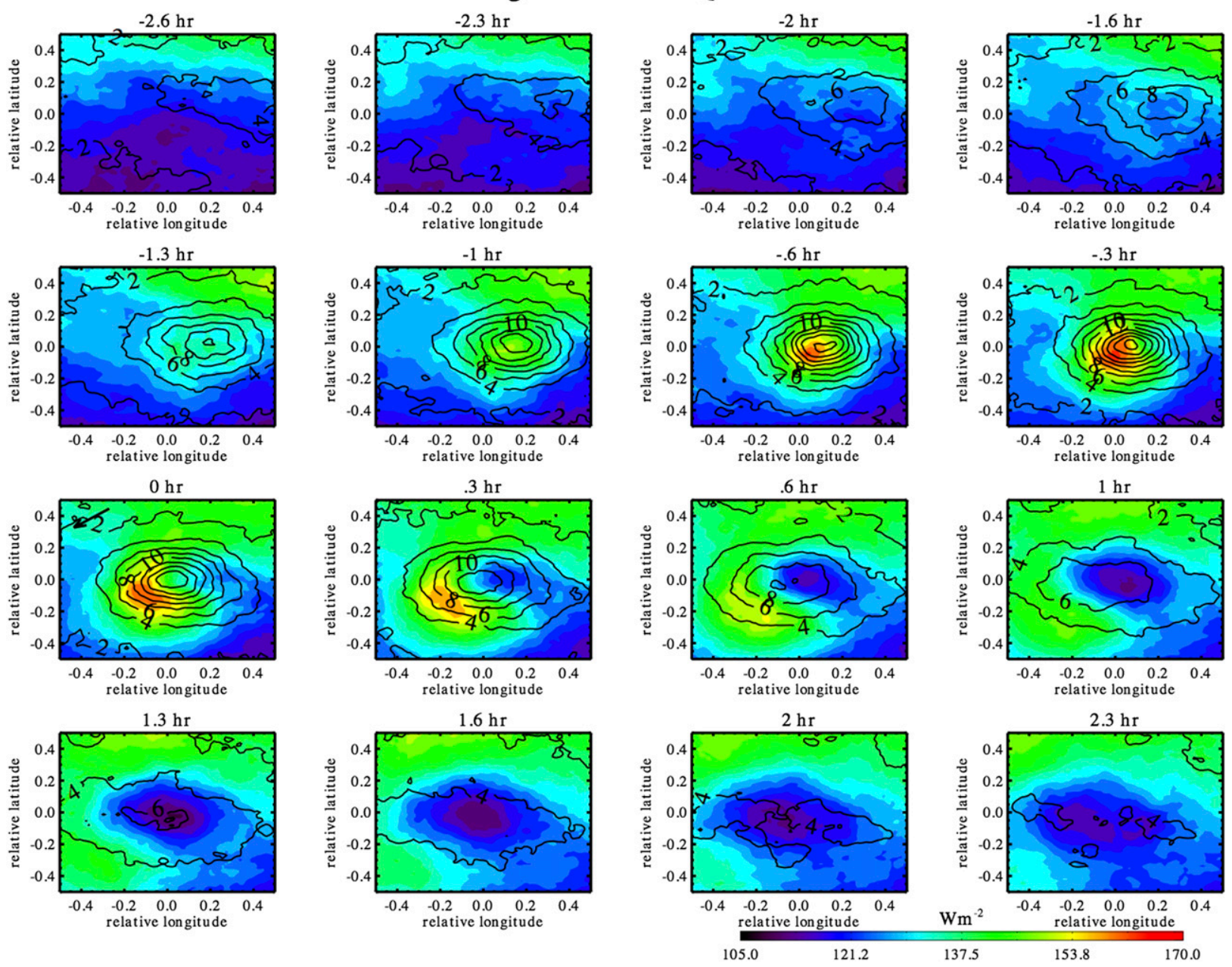

FIG. 11. As in Fig. 7, but for cluster falling into the second-size quartile during the onset regime; here, precipitation contours are $2.0 \mathrm{~mm} \mathrm{~h}^{-1}$. Note that the LHFLX range is different than Fig. 7. The magnitude of the mean wind vector is $2.0 \mathrm{~m} \mathrm{~s}^{-1}$.

variations. Before $t=0$, winds are stronger on the upwind half of the domain with indications of convergence along the $0^{\circ}$ latitude line near the lowest wind speeds. At and after $t=0$, enhanced wind speed occurs downwind of the precipitation maximum and diminished wind speeds upwind of the precipitation maximum. This enhanced versus diminished wind speed couplet is likely the composite structure of downdraft winds at the surface creating a gust front in all directions that constructively or destructively interferes with the background wind. Wind speeds are enhanced ahead of the precipitation maximum where gust-front winds are in the same direction as the background wind while weakened behind since the gust-front winds there oppose the background wind. Supplementary Fig. S2 is the same as Fig. 8, but for the 4Ctrl0 simulation. Again, the evolution of wind and precipitation in the $4 \mathrm{Ctrl0}$ simulation is qualitatively similar to the $1.5 \mathrm{Ctrl0}$ simulation, while the wind speed and precipitation values are weaker in the 4Ctrl0 simulation.

Figure 9 shows composites of lowest model level (i.e., $34.6 \mathrm{~m}$ ) specific humidity. We only show $q$ at the lowest model level since SST does not vary over the composite time shown. Composites of $q$ confirm that the finescale structure of LHFLXs are predominately wind driven as the $q$ composites lack the couplet structure that the wind composites show. However, $q$ appears to contribute to the broader LHFLX structure. Relatively high $q$ values before $t=0$ help to set the location and magnitude of the minimum LHFLX during this time as relatively high near-surface air q leads to smaller $\Delta q$ values and hence lower LHFLXs. Before $t=0$, the location of the minimum LHFLXs are somewhat offset from the minimum wind speeds toward the region of maximum 


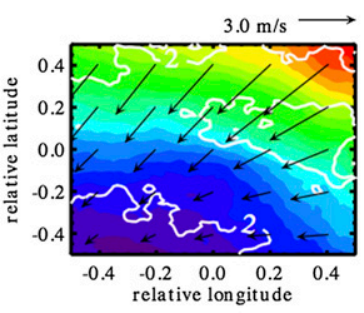

\section{On set Regime $2^{\text {nd }}$ Size Quartile}
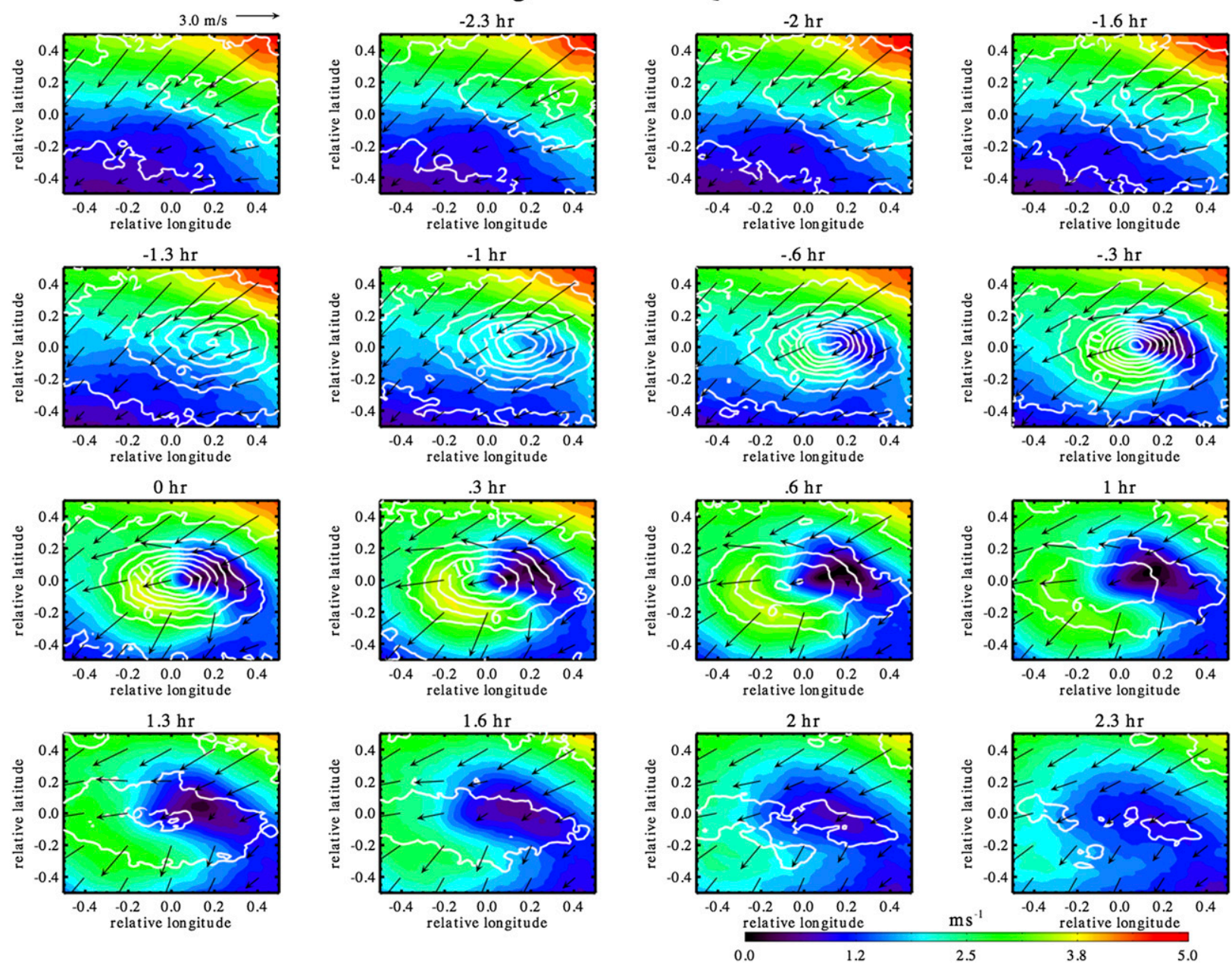

FIG. 12. As in Fig. 8, but for clusters in the second-size quartile during the onset regime. Note that the wind speed range is different than Fig. 8.

$q$ (cf. Figs. 7-9). As $t=0$ is approached, the area of relatively high $q$ values contracts in size along with the region of relatively low LHFLXs. These relatively high $q$ values appear to be caused by moisture convergence by the composite winds in association with gust-front convergence (cf. Figs. 8 and 9). The magnitude of LHFLX and humidity changes across the composites of these small clusters is similar in magnitude to the composites of radar-observed submesoscale systems tracked in Yokoi et al. (2014).

During the onset and WWB regimes, the overall evolution of LHFLXs surrounding clusters in the smallest-size quartile is dominated by the background wind. Figure 10, which is the same as Fig. 7, but for the smallest-size quartile clusters in the WWB, reveals LHFLXs are consistently higher in the southwest half of the domain compared to the northeast half regardless of the precipitation evolution. This persistent flux signal is contributed by the large-scale wind. However, a relative maximum in LHFLX occurs downwind of the precipitation maximum at $t=0$ with a relative minimum in LHFLX upwind. Both the precipitation maximum and LHFLX couplet surrounding the precipitation maximum propagate northeast along the mean wind vector as time progresses. A similar LHFLX-precipitation structure and evolution are seen for the smallest-size quartile clusters during the onset regime, except the highest LHFLXs are in the north-northeast half of the domain, while the lowest LHFLX are in the opposite half, since the mean wind vector during this regime is to the southwest (not shown). The flux perturbations localized to convection during the onset and WWB regimes create a fractionally smaller increase in fluxes relative to the background (i.e., domain averaged) state when 
compared to the suppressed period, since the background wind speed and LHFLX are much lower during the suppressed period.

The LHFLX couplet surrounding the precipitation for the smallest-size quartile clusters in the onset and WWB regime is smaller in spatial scale than those in the suppressed regime, though still present, indicating a consistent relationship between local precipitation and LHFLX variations. However, in the onset and WWB regime, the higher background wind compared to the suppressed regime appears to limit the spatial scale in which the gust front from the smallest-size quartile clusters can influence the surrounding LHFLX.

\section{2) SECOND-, THIRD-, AND LARGEST-SIZE QUARTILE CLUSTERS}

Clusters in the second-size quartile for all three regimes show a similar LHFLX-precipitation relationship and evolution relative to the background wind vector as their smallest-sized quartile counterparts (cf. Figs. 7, 10, and 11). Only clusters in the second-size quartile of the onset regime are shown (Fig. 11) since the second-size quartile clusters during the suppressed and WWB regimes showed very similar composites, except the LHFLXs and precipitation evolve along the southeastand northeast-pointing wind vector, respectively, instead of along the southwest wind vector. Whereas the LHFLX-precipitation relationship for the smallest-size quartile clusters in the onset and WWB regime was dominated by the background wind with only a moderate LHFLX couplet surrounding the precipitation (Fig. 10), these larger clusters are able to generate a noticeable outflow signature compared to the background wind (Fig. 12), thereby generating a distinct LHFLX couplet around the precipitation maximum. Wind speeds and LHFLXs grow in strength downwind of the precipitation center starting around $t=-0.6 \mathrm{~h}$, and wind vectors hint at divergence downwind of precipitation starting around $t=0$ (Figs. 11 and 12). The composites of these larger clusters (i.e., Figs. 11 and 12) indicate that a noticeable LHFLX couplet surrounding precipitation maxima can exist even in the presence of strong background winds.

Qualitatively, the evolution of precipitation and LHFLX for clusters in the third-size quartile is similar to the smaller-size clusters of the respective MJO regimes (not shown). The main difference for clusters in the third-size quartile is the noisiness of the composites due to the fewer events that compose the composites (Table 1). Composites around the center of clusters in the largest-size quartile are not meaningful as there are comparatively very few clusters in this size regime (Table 1) and the resulting composites are extremely noisy.

\section{3) SUMMARY OF LHFLX-PRECIPITATION RELATIONSHIP}

Regardless of MJO regime, the LHFLX-precipitation relationship for clusters in the first three size quartiles evolves as follows: Before $t=0$, a maximum in LHFLX occurs upwind of the developing precipitation center. As $t=0$ is approached, the LHFLX and precipitation maxima start to collocate. After $t=0$, maximum LHFLXs move downwind of the precipitation center, with a minimum in LHFLX occurring upwind. We interpret this signal as constructive versus destructive interference of cluster downdraft outflow winds and the background wind.

Findings in this subsection are consistent with previous work that showed enhanced surface fluxes associated with increased winds generated by convective outflow (e.g., Young et al. 1995; Jabouille et al. 1996; Esbensen and McPhaden 1996; Saxen and Rutledge 1998; Redelsperger et al. 2000), as well as with Hagos et al. (2013), who found in their regional CRM over the Maritime Continent and tropical west Pacific that enhanced LHFLXs occur upwind of maximum precipitation during the initial stages of a convective system's life cycle yet occur downwind of the maximum precipitation toward the end of the convective system's life cycle. Having established a robust LHFLXprecipitation relationship, we now test whether these convective-scale LHFLX signatures are important for organizing convection within the MJO as some modeling studies have done for idealized scenarios (e.g., Tompkins and Craig 1998; Muller and Held 2012; Holloway and Woolnough 2016; Gentine et al. 2016).

\section{Comparison of cluster characteristics for the 4-km control versus sensitivity simulations}

Figure 13 is analogous to Fig. 5, but shows histograms of total cluster area for the various $4-\mathrm{km}$ sensitivity simulations compared to their control simulations (Figs. 13a-c). The two 4-km control simulations are also compared (Fig. 13d) in order to evaluate how changing the initial condition alters the size distribution of clusters. Vertical lines in each panel indicate the size quartile thresholds. The black histograms in Figs. 13a,b,d are the same as the red histogram in Fig. 5. As before, each quartile bin contains $25 \%$ of the total cluster area. There is no consistent or systematic shift in the size quartiles between the control and sensitivity simulations. For example, the threshold for clusters contained within the smallest-size quartile (leftmost dashed lines) is smaller 
a)

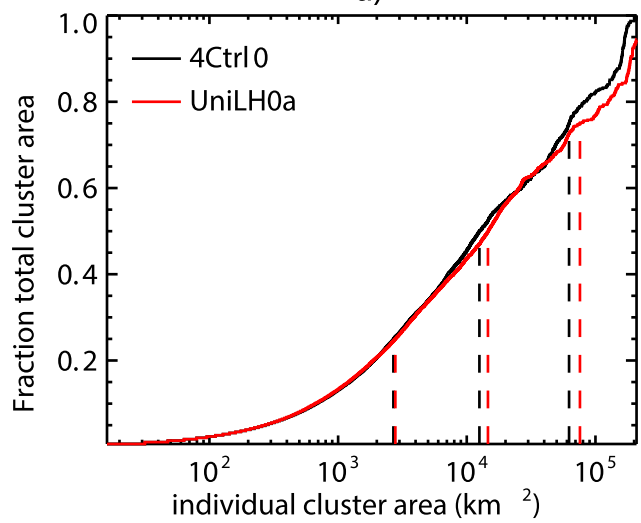

C)

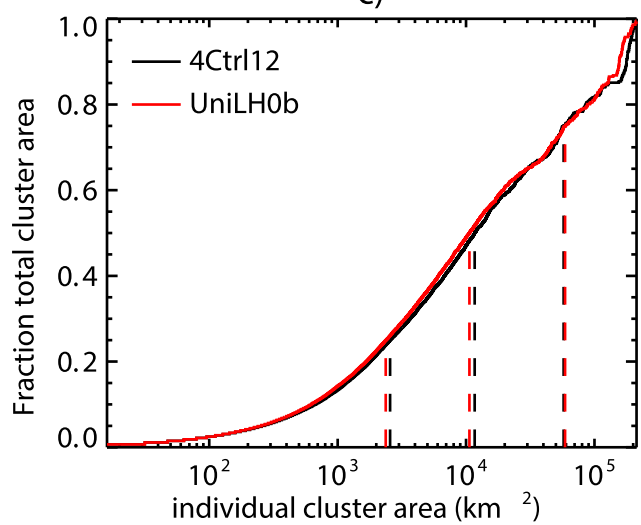

b)

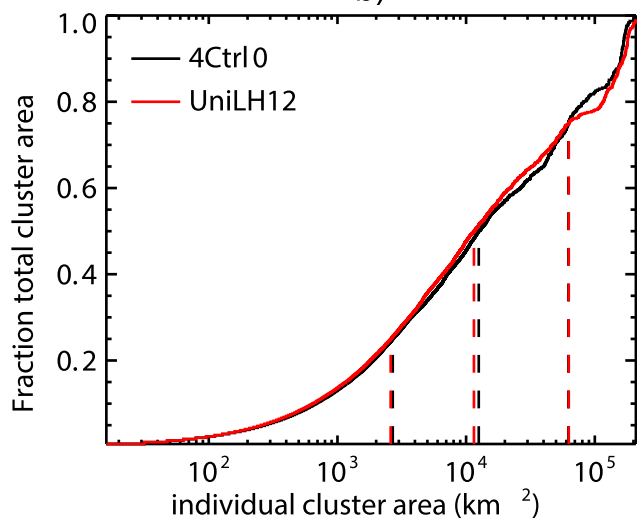

d)

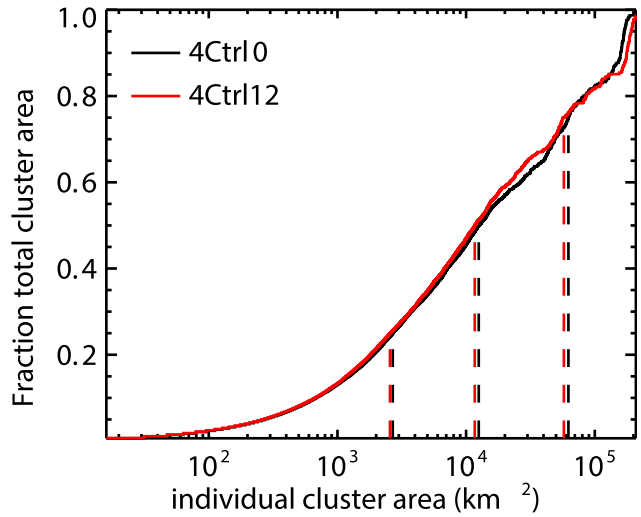

FIG. 13. Cumulative histogram of cluster area for the (a) 4Ctrl0 simulation (black) and UniLH0a simulation (red), (b) 4Ctr10 simulation (black) and UniLH12 simulation (red), (c) 4Ctrl12 simulation (black) and UniLH0b simulation (red), and (d) 4Ctrl0 simulation (black) and 4Ctrl12 simulation (red). Dashed vertical lines indicate the size-quartile thresholds and, from left to right, are the smallest-, second-, third-, and largest-size quartiles. These plots are analogous to Fig. 5.

in two of the uniform LHFLX sensitivity simulations (Figs. 13b,c) but larger in another (Fig. 13a) when compared to its parent control simulation. Size quartile threshold differences between the control and sensitivity simulations (black vs red vertical lines in Figs. 13a-c) are of the same order of magnitude as size quartile threshold differences between the two control simulations (black vs red lines in Fig. 13d), except for the thirdand largest-size quartiles in the 4Ctrl0 versus UniLH0a simulations (Fig. 13a). This indicates, at least for these simulations, that the size distribution differences due to homogenizing LHFLXs are generally not greater than differences in the size distributions due to altering only the initial conditions.

Figure 14 compares the $4 \mathrm{Ctrl} 0$ distribution of clusters by day for each size quartile to the analogous UniLH0a (Figs. 14a-d) and UniLH12 (Figs. 14e-h) distributions. The distribution of clusters across days within a given size quartile does not systematically change between the control and sensitivity simulations. Specifically, the shapes of the distributions are similar. Also, the differences (Fig. 14, blue histogram) are not consistent within a particular MJO regime or even from day to day despite sometimes having values on the same order as the absolute values of the histograms (e.g., 10 November in the second-size quartile; Figs. 14b,f). For example, differences within the second-size quartile switch from positive to negative several times during the MJO suppressed regime.

Figure 15 shows composites of wind speed, wind vectors, and precipitation for $1.3 \mathrm{~h}$ before to $1 \mathrm{~h}$ after cluster identification for clusters in the second-size quartile during the suppressed regime for the $4 \mathrm{Ctrl} 0$, UniLH0a, and UniLH12 simulations. Overall, the composites between the control and sensitivity simulations are similar in structure (i.e., the shape of and the relationship between wind speed and precipitation are similar), suggesting that the localized enhanced fluxes 
associated with convective gust fronts have little influence on surface precipitation structure and evolution for convective elements. The wind speed structure in the UniLH0a simulation differs from the 4Ctrl0 simulation in that the relatively large wind speeds occur on both the northeast and southeast flanks of the maximum precipitation as opposed to just the southeast flank as in the 4Ctrl0 simulation. However, this is not a consistent difference among the sensitivity simulations (Fig. 15a vs Fig. 15c). There are similar composite comparisons between control and sensitivity simulations for the other size quartiles and $\mathrm{MJO}$ regimes and across the longer time span of $4 \mathrm{~h}$ before and after cluster identification (not shown).

\section{Convective organization sensitivity to LHFLXs in the 4-km simulations}

\section{a. Quantifying convective organization}

Convective organization is quantified in two ways: 1) using the simple convective aggregation index (SCAI) developed by Tobin et al. (2012) and 2) comparing the area-averaged convective versus stratiform rain. For the purpose of achieving the goal of this study - to examine how surface LHFLXs alter convective organizationwe are interested in the changes of SCAI and areaaveraged convective versus stratiform rain between the 4-km control and sensitivity simulations rather than how the two metrics are related to each other. We used two measures of organization to check for consistency in changes between the 4-km control and sensitivity simulations and increase the robustness of our results.

The SCAI quantifies convective aggregation by accounting for the number of clouds $(N)$ and distance between clouds $\left(D_{0}\right)$ for a given cloud scene (Tobin et al. 2012) and is defined as

$$
\mathrm{SCAI}=\left(\frac{N}{N_{\max }}\right)\left(\frac{D_{0}}{L}\right) \times 1000,
$$

where $N_{\max }$ is the maximum number of clusters possible (dimensionless) within a given domain, $D_{0}$ is the mean distance $(\mathrm{km})$ between all possible cluster pairs in a cloud scene, and $L$ is the horizontal size $(\mathrm{km})$ of the domain. Tobin et al. (2012, p. 6890) interpret the formula as the "ratio of the degree of convective "disaggregation' to a potential maximal disaggregation, expressed in per thousand." In Tobin et al. (2012), only $T_{B}$ was used to identify clouds (or clusters), whereas here, we use both $T_{B}$ and precipitation. Cloud scenes with smaller SCAI values are considered more organized. If either $N$ or $D_{0}$ remains the same, SCAI may still decrease (and, hence, the scene would be considered more organized) if the nonfixed variable decreases. The $N_{\max }$ was assigned as the largest value of $N$ over all model times for each simulation; $D_{0}$ was determined for all cluster pairs as the distance between the areaweighted centers of each cluster pair.

Convective cloud scenes containing MCSs or more MCSs than small isolated deep convection are generally considered more organized because of MCS's larger size and longer life span and their greater impact on the largescale circulation compared to small isolated deep convection (e.g., Houze 2004). A defining characteristic of MCSs is the presence of stratiform rain (e.g., Houze 2004). Therefore, shifts in the contribution to the total precipitation away from convective area to more stratiform area are typically considered to be representative of more organized convection. For example, Schumacher and Houze (2003) discuss how increases in stratiform rain fraction over land are often associated with increases in organized precipitating systems. Convective and stratiform rain are determined from model-derived radar reflectivity at $2.4 \mathrm{~km}$, following Yuter and Houze (1997), which is based on the Steiner et al. (1995) algorithm. The algorithm uses reflectivity intensity and peakedness to distinguish the two rain types.

\section{b. The 4-km control versus sensitivity simulation organization}

Figure 16a shows that differences between domainmean precipitation for the 4-km control and sensitivity simulations and between the two 4-km control simulations are noisy around the zero line. The similarity among precipitation was expected since all simulations have the same SST evolution and lateral boundary nudging and, hence, domain-mean moisture flux. Figure $16 \mathrm{~b}$ shows SCAI differences between the $4-\mathrm{km}$ control and sensitivity simulations and the two 4-km control simulations. Evolution of SCAI throughout the November MJO is dominated by the evolution of $N$ (not show), which is similar to the findings of Tobin et al. (2012). There is no consistent difference in SCAI between the 4-km control and sensitivity simulations suggesting convective organization is not affected by local variability in LHFLXs. For example, during 23 November, the UniLH0b simulation showed less organized convection than its parent $4-\mathrm{km}$ control simulation (i.e., blue line is positive), while the other two uniform LHFLX simulations had more organized convection (i.e., black and red lines are negative). Recall, a smaller SCAI value indicates more organized convection. Also, the SCAI differences are noisy as they vary from positive to negative from day to day. Differences between $4-\mathrm{km}$ control and sensitivity simulations are generally on the same order of magnitude as the differences between the two 4-km control simulations, suggesting differences caused 

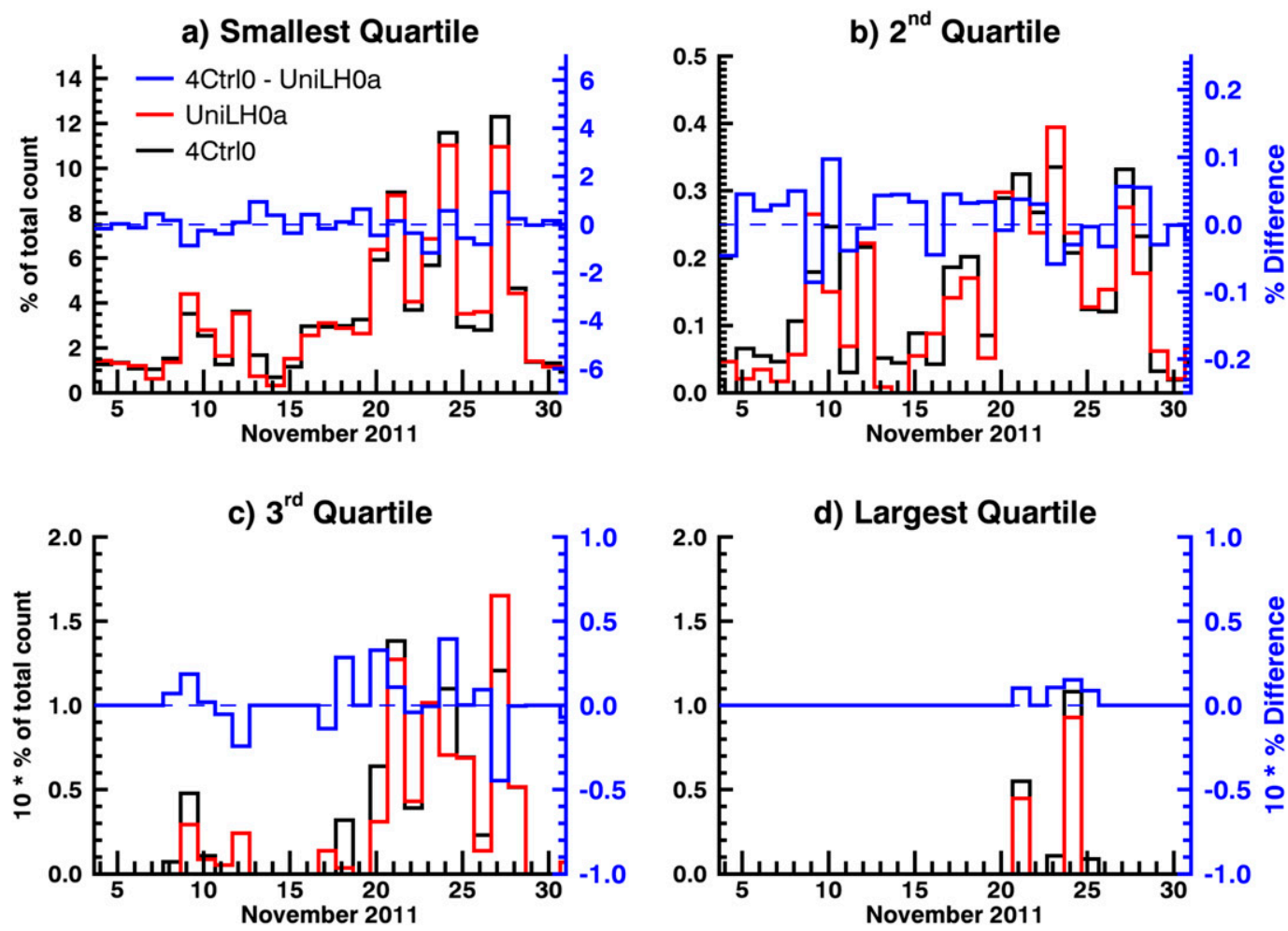

d) Largest Quartile

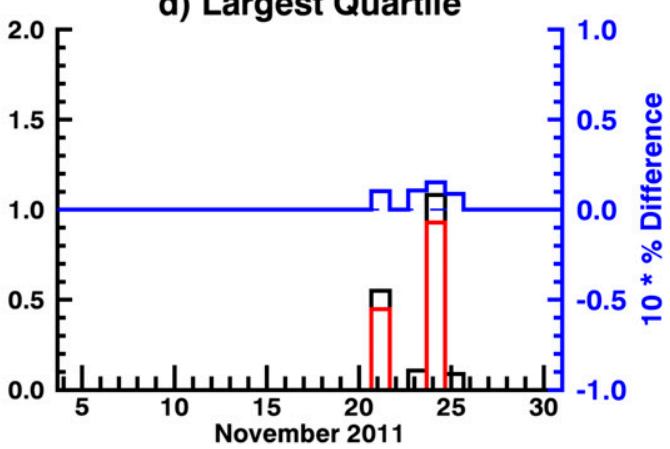

e) Smallest Quartile

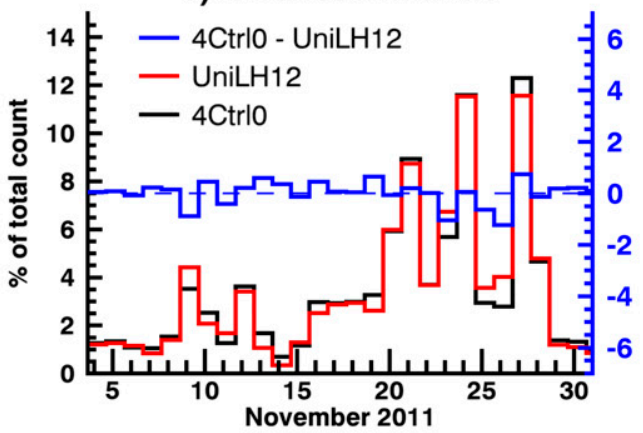

f) $2^{\text {nd }}$ Quartile
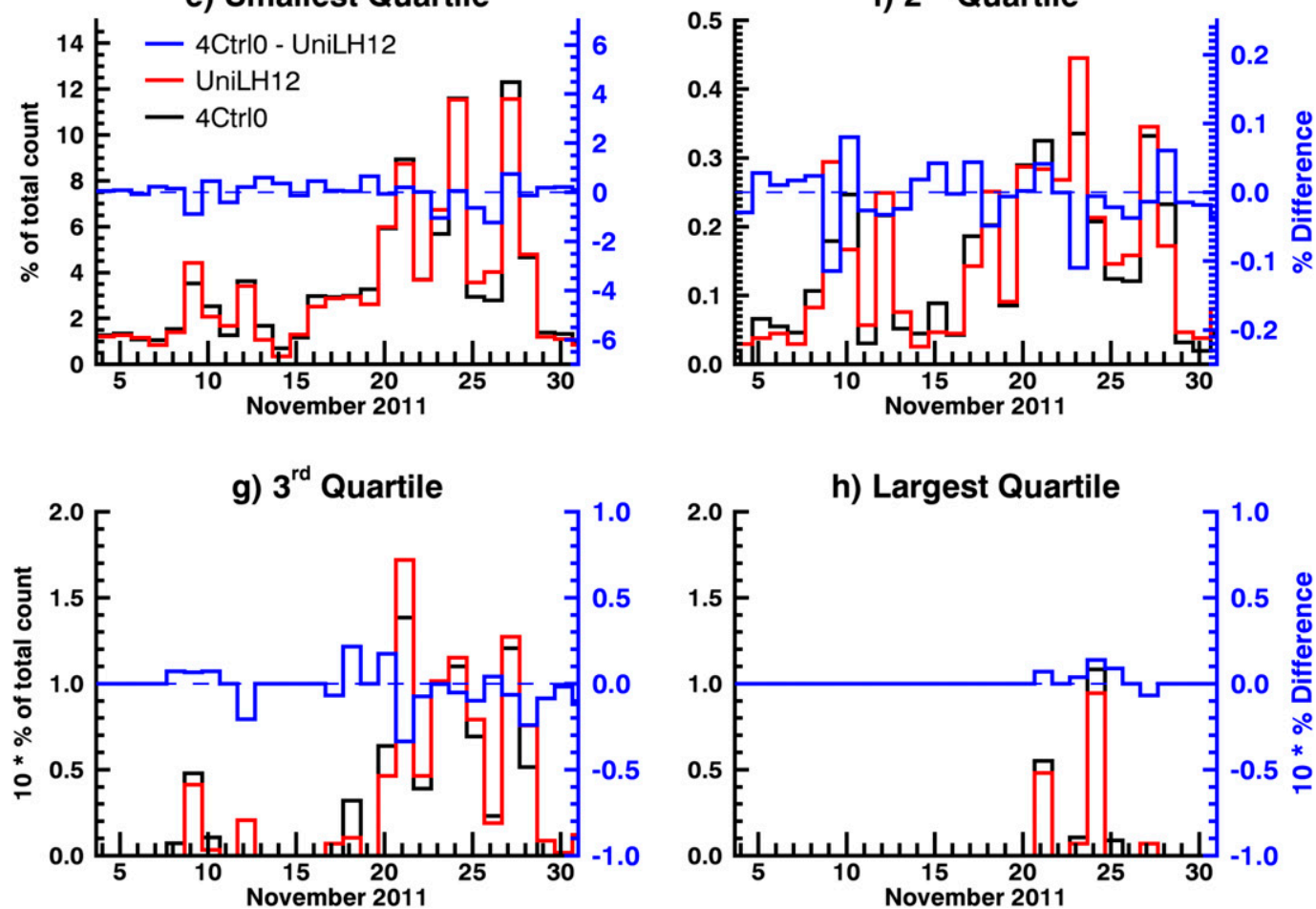

FIG. 14. Histograms of the percent count of clusters that occur on each day for the indicated size quartile in the (a)-(d) 4Ctrl0 simulation (black) and UniLH0a simulation (red). The blue histogram is the difference between the indicated control and sensitivity simulations' histograms (i.e., black minus red histograms). The right blue $y$ axis corresponds to the blue histogram. The dashed horizontal blue line indicates zero difference. (e)-(h) As in (a)-(d), 
by the homogenization of LHFLXs have a similar degree of importance to SCAI changes as do the initial condition differences.

Figure 17 shows area-averaged precipitation for convective, stratiform, and total rain for the 4-km control versus sensitivity simulations (Figs. 17a-c) and for the two control simulations (Fig. 17d). These plots are analogous to Fig. 3a of Xu and Rutledge (2014), who partitioned area-averaged precipitation from the TOGA radar onboard the R/V Revelle during DYNAMO into convective and stratiform rain. There is no identifiable difference in convective- and stratiform-area precipitation between the 4-km control and sensitivity simulations, suggesting, as the SCAI analysis did, that convective organization remains the same among the various $4-\mathrm{km}$ control and sensitivity simulations, indicating local variability in LHFLXs are not important for organizing convection. Difference plots between 4-km control and sensitivity or the two 4-km control simulations were noisy around zero like the SCAI difference plots (not shown).

\section{Discussion}

Sensitivity simulations with spatially homogenized LHFLXs did not consistently and systematically alter organization of convection within the MJO compared to the 4-km control simulations (variable LHFLXs), at least in the ways that we quantified organization and in the distribution of clusters among size quartiles and regimes. Also, composites of precipitation and wind were similar between the 4-km control and sensitivity simulations. These results suggest that for the simulations discussed in this study, the LHFLX variations on the local scale surrounding convection and associated with convective gust fronts do not play an important role in convection organization or evolution. We discuss three possible explanations for our results: 1) large-scale forcing, as opposed to local convective-scale feedbacks, is more important for convective organization; 2 ) mechanical lifting associated with the cold pool gust front is more influential at organizing convection compared to the thermodynamic feedbacks associated with surface fluxes; and 3) processes such as radiative feedbacks dominate convective organization compared to the role surface flux feedbacks have in convective organization. None of these possible explanations are verified by our current analysis and results. Only the second explanation is consistent with our results (as discussed below). Additional sensitivity experiments would be necessary to test and verify the three possible explanations.

It is plausible that, in our simulations, the large-scale dynamics and/or SST variations were more important for determining convective organization than windinduced LHFLX feedbacks. Previous studies that did show changed convective organization due to altered surface flux feedbacks were highly idealized. The 3D CRM simulations of Tompkins and Craig (1998), which exhibited altered convective organization when windinduced flux feedbacks were removed, were RCE runs with fixed homogeneous SSTs and no imposed largescale convergence or mean wind shear. Likewise, Gentine et al. (2016) used a CRM with no vertical wind shear, prescribed radiation, and homogeneous SSTs to show that fixed flux simulations produced more organized convection than in interactive flux experiments. In their simulations, the interactive surface flux simulations were less organized because of the production of smaller, more numerous cold pools compared to the fixed surface flux simulations. However, as mentioned in the introduction, Holloway and Woolnough (2016) suggest that feedbacks that are seemingly important in idealized models may be less so in the real world. They posit that, in nature, large-scale forcing may be conducive to smaller-scale convective clustering, rendering surface flux feedbacks unimportant for convective organization. In Holloway (2017), with simulations of real case studies, they highlight the importance of large-scale forcing at the model domain boundaries for organizing convection, which may also be relevant in our simulations. Our future work will test the role of the large-scale boundary forcing in convective organization by eliminating boundary nudging and instead employing a spectral weak temperature gradient (WTG) approach to parameterize largescale dynamics (e.g., Herman and Raymond 2014; Wang et al. 2016; Ruppert and Johnson 2016).

An alternative explanation for our results is that local, small-scale processes associated with convectively generated gust fronts are still important for convective organization; however, it is the dynamical as opposed to thermodynamic processes that drive the organization.

\footnotetext{
but for the 4Ctr10 simulation (black) and UniLH12 simulation (red). The legend in (a) applies to (a)-(d), while the legend in (e) applies to (e)-(h). The sum of all size quartiles and days for the histograms equals $100 \%$. Black histograms are the same as the red histograms in Figs. 6e-h. Size quartiles were based on each simulation's size thresholds shown in Fig. 13.
} 
a) $4 \mathrm{Ctr} 10$

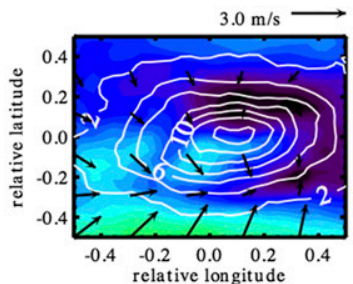

$0 \mathrm{hr}$

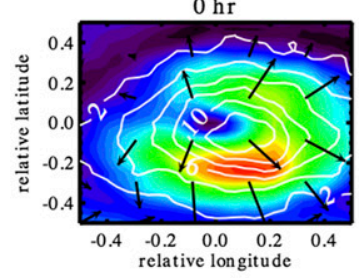

b) UniLH0a
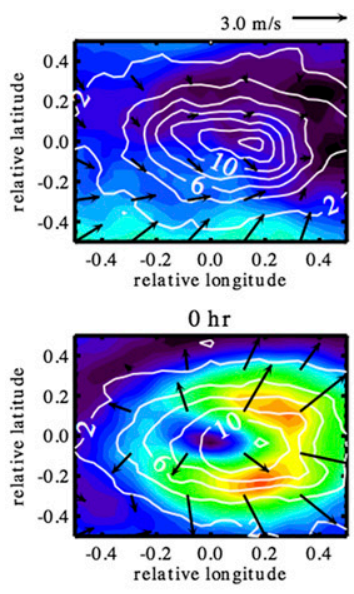

c) UniLH 12

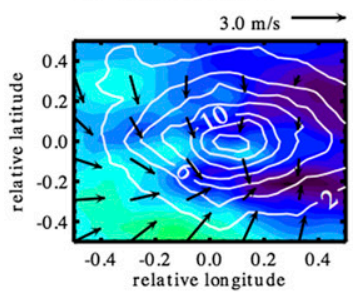

$0 \mathrm{hr}$

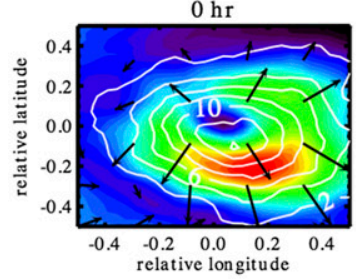

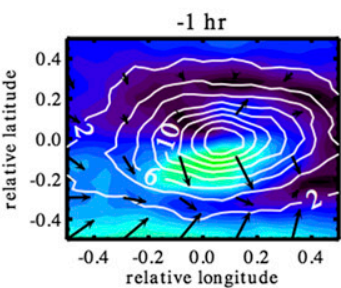

$.3 \mathrm{hr}$

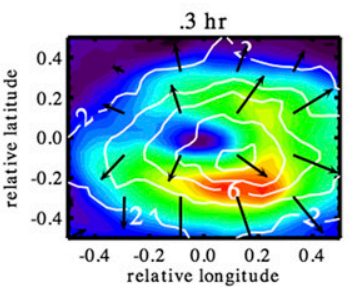

relative longitude

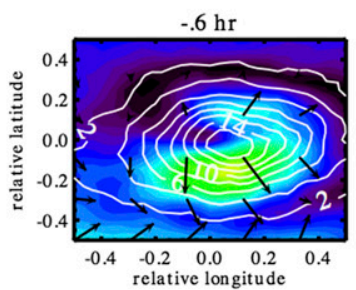

$.6 \mathrm{hr}$

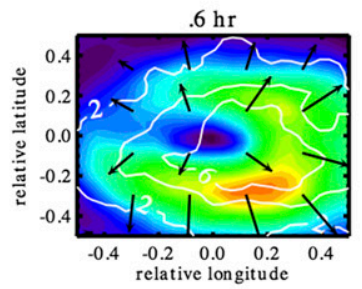

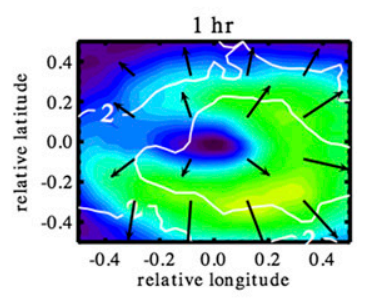

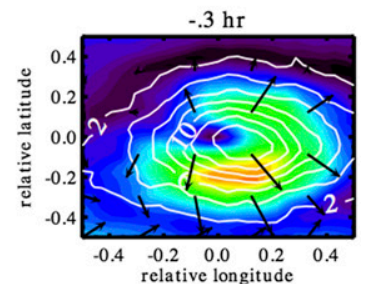

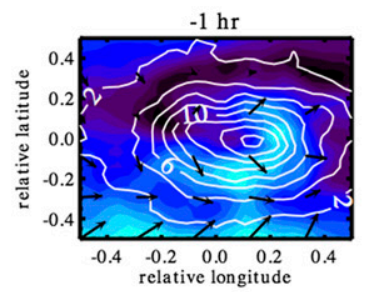
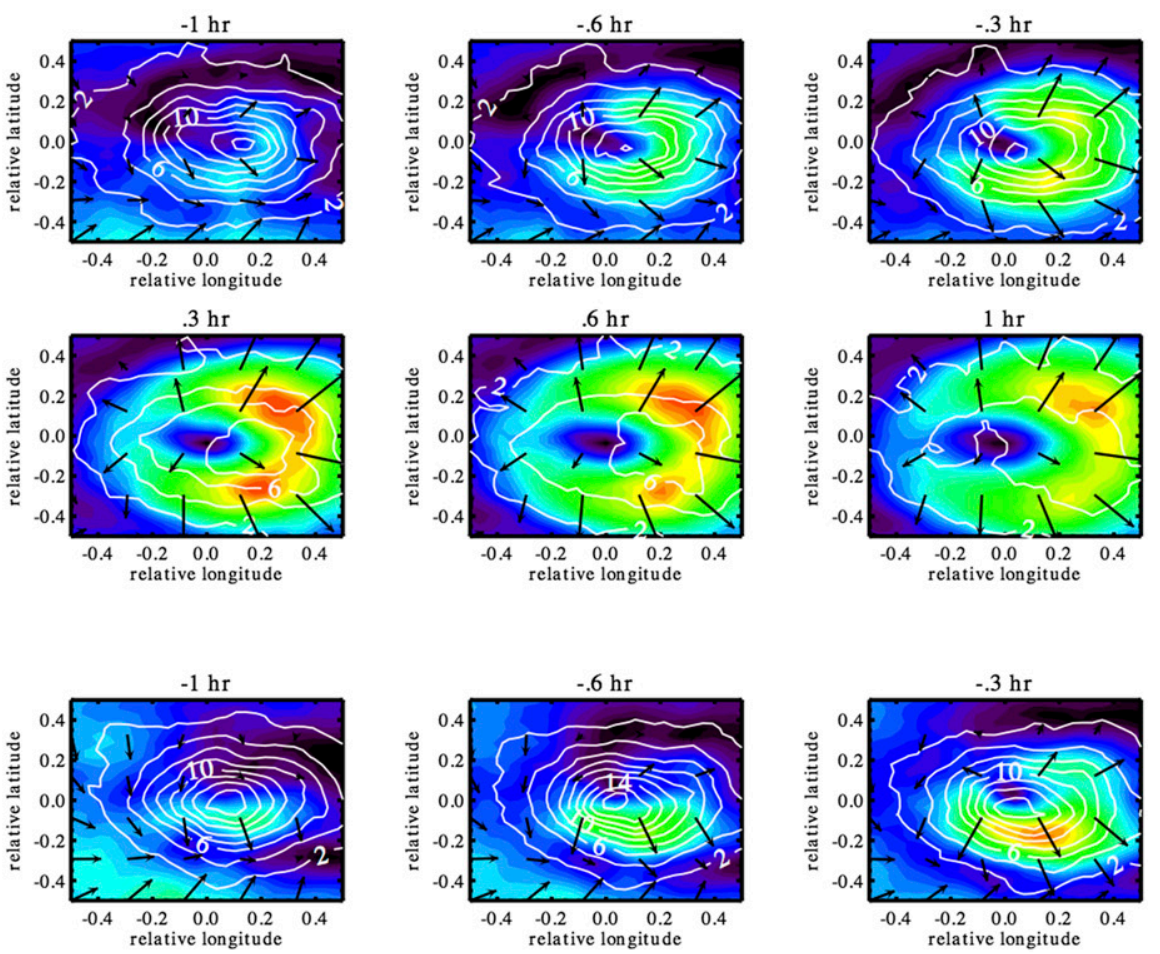

$.3 \mathrm{hr}$
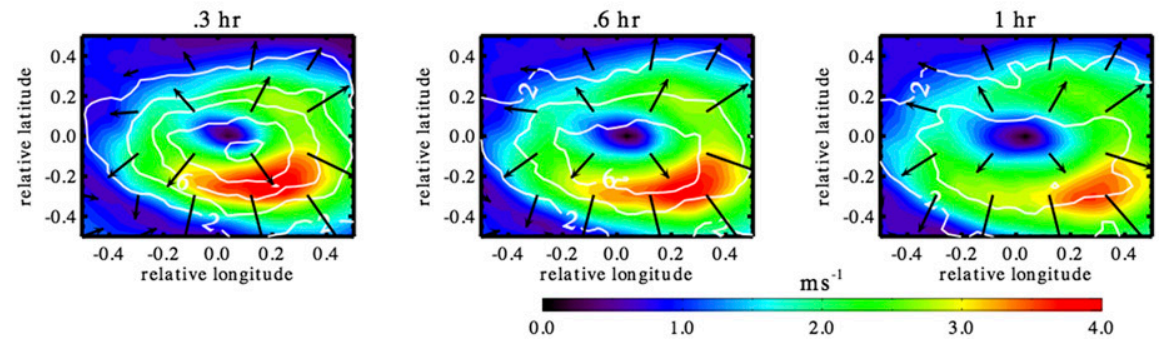

0.0

FIG. 15. Composites of wind speed (color shading), wind vectors, and precipitation (white contours) for $1.3 \mathrm{~h}$ before to $1 \mathrm{~h}$ after cluster identification for clusters in the second-size quartile and suppressed regime for the (a) 4Ctrl0 simulation, (b) UniLH0a sensitivity simulation, and (c) UniLH12 sensitivity simulation. Precipitation contours are every $2 \mathrm{~mm} \mathrm{~h}^{-1}$ with every other contour labeled. In each section, the top-left panel is $t=-1.3 \mathrm{~h}$ and shows the reference wind vector. 

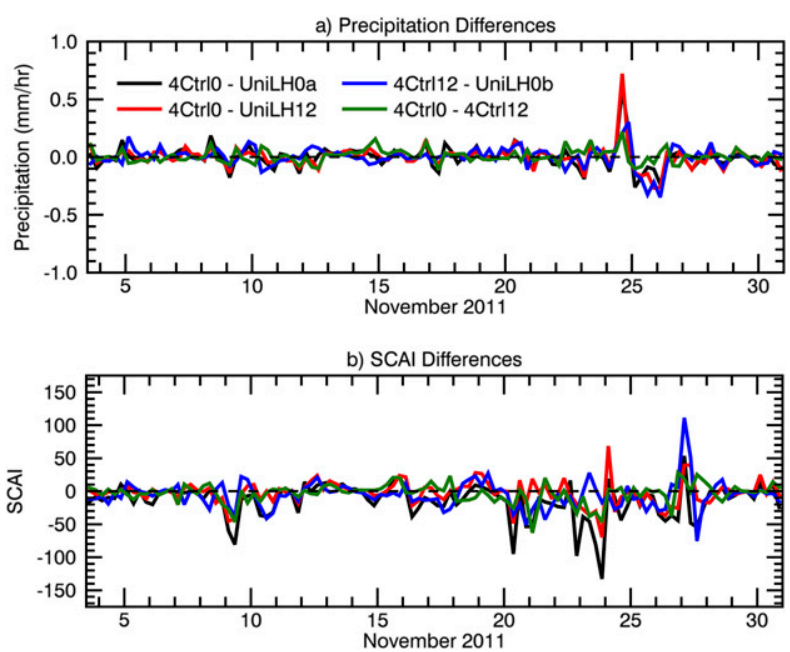

FIG. 16. (a) Domain-averaged precipitation differences between indicated 4-km control and sensitivity simulations and the two control simulations. (b) SCAI differences for indicated 4-km control and sensitivity simulations and the two 4-km control simulations. The color legend in (a) also applies to (b). For all panels, the time series has been averaged from the 20-min output time to 6-hourly to reduce noisiness when comparing simulations. The dashed black line indicates zero difference.

While the gust-front-enhanced fluxes have been shown in our simulations to be unimportant for convective organization, the gust fronts are perhaps influencing convective organization through mechanical lifting of parcels to their level of free convection. Though contrary to the results of Tompkins (2001), who found the thermodynamic effect as the dominant organizing agent of subsequent convection along cold pools, more recent work has found the dynamic effects are at least as important as the thermodynamic effects. Li et al. (2014) found the dynamical lifting process of cold pools more influential than the thermodynamic forcing. Their study only looked at trade wind cumulus, so their conclusions may not be highly relevant to our study. However, Jeevanjee and Romps (2015) looked at deep convection and also found the dynamical lifting process along cold pools to be the dominant process. Similar results were found in Torri et al. (2015), although they concluded the dominance of lifting versus thermodynamic effects is most relevant near the surface. After the parcel has ascended, the thermodynamic effect from the presence of the cold pool becomes important, as the parcel is moister than it would otherwise be in the absence of surface fluxes associated with the gust front. Skyllingstad and de Szoeke (2015) also find both dynamic and thermodynamic process associated with the cold pool to be important for the organization of convection. The lack of convective organization changes between the $4-\mathrm{km}$ control and sensitivity simulations (Figs. 16 and 17) along with the similar structure, evolution, and intensity of gust fronts among the heterogeneous versus homogeneous LHFLX simulations (Fig. 15) is at least consistent with the idea that mechanical lifting along the gust front may be important for convective organization. Future work will include identification, tracking, and characterization of cold pools within our simulation to decisively discern what processes (dynamic vs thermodynamic) along the simulated gust fronts are organizing convection.

Another explanation for our results is that other feedbacks such as radiative feedbacks may dominate over flux feedbacks in determining convective organization. The dominance of radiative versus surface flux feedbacks would agree with self-aggregation studies that show radiative feedbacks are important for both initiating and maintaining aggregation, whereas surface flux feedbacks may only be important for initiating aggregation (e.g., Bretherton et al. 2005; Muller and Held 2012; Wing and Emanuel 2014; Holloway and Woolnough 2016). Anomalous composites (i.e., anomalies relative to the \pm 4 -h composite mean) of LHFLX and OLR for the 1.5Ctrl0 simulation showed that the OLR anomalies are smaller than the LHFLX anomalies (not shown), casting doubt on the possibility that radiative flux feedback may dominate over LHFLX feedbacks when viewing the importance of these processes in the context of the vertically integrated moist static energy budget. However, sensitivity tests similar to Holloway (2017) with 1) constant radiative cooling and 2) uniform LHFLXs and constant radiative cooling should be done for these DYNAMO experiments to verify the role of radiative feedbacks and the combined effect of radiative feedback and LHFLXs on organizing convection.

\section{Summary}

This work simulated the November DYNAMO MJO event using the RAMS CRM to examine the LHFLXprecipitation relationship for clusters within various $\mathrm{MJO}$ regimes and determine the importance of convectivescale wind-induced LHFLX feedbacks for organizing convection within the MJO. Two types of simulations were conducted: 1) 1.5- and 4-km control simulations with interactive surface fluxes were used to establish the relationship between wind-induced LHFLXs and convection, and 2) sensitivity simulations with spatially homogenized, yet temporally evolving, LHFLXs were used to determine how LHFLX variations affected convective organization. The main findings of this paper are the following: 
a) 4 Ctrlo vs. UniLHOa

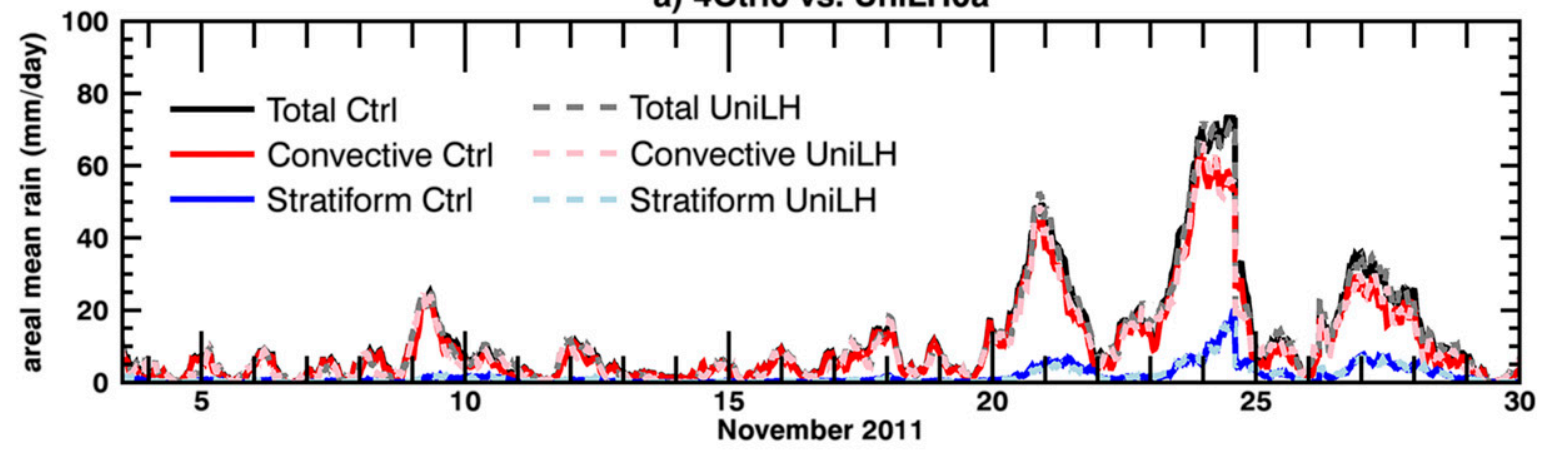

b) 4 Ctri0 vs. UniLH12

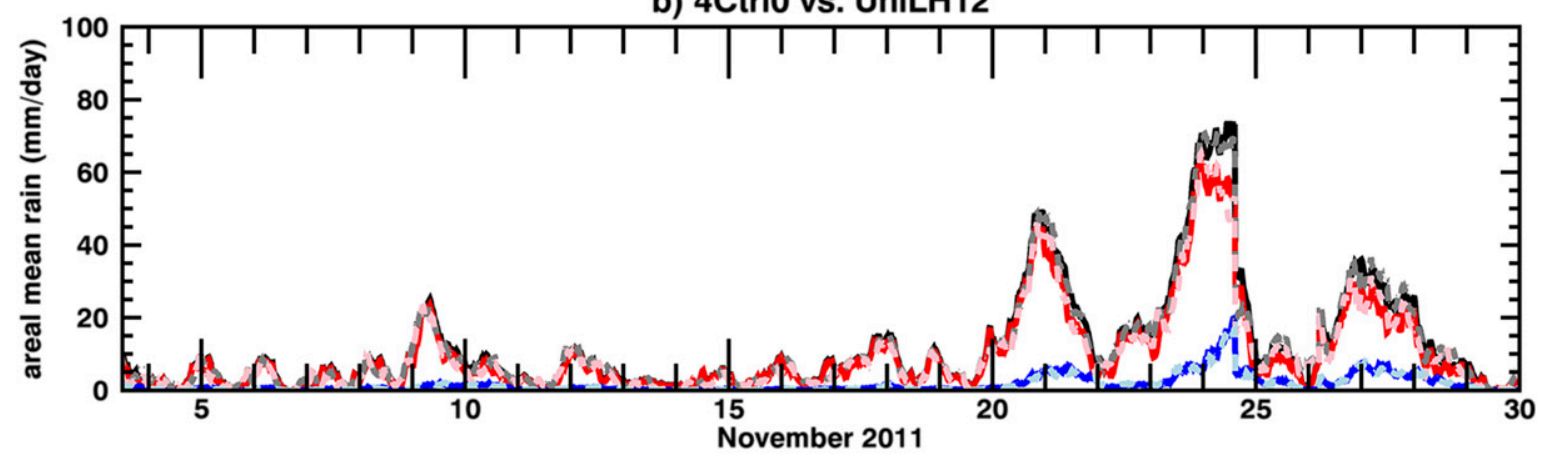

c) 4 Ctrl12 vs. UniLHOb

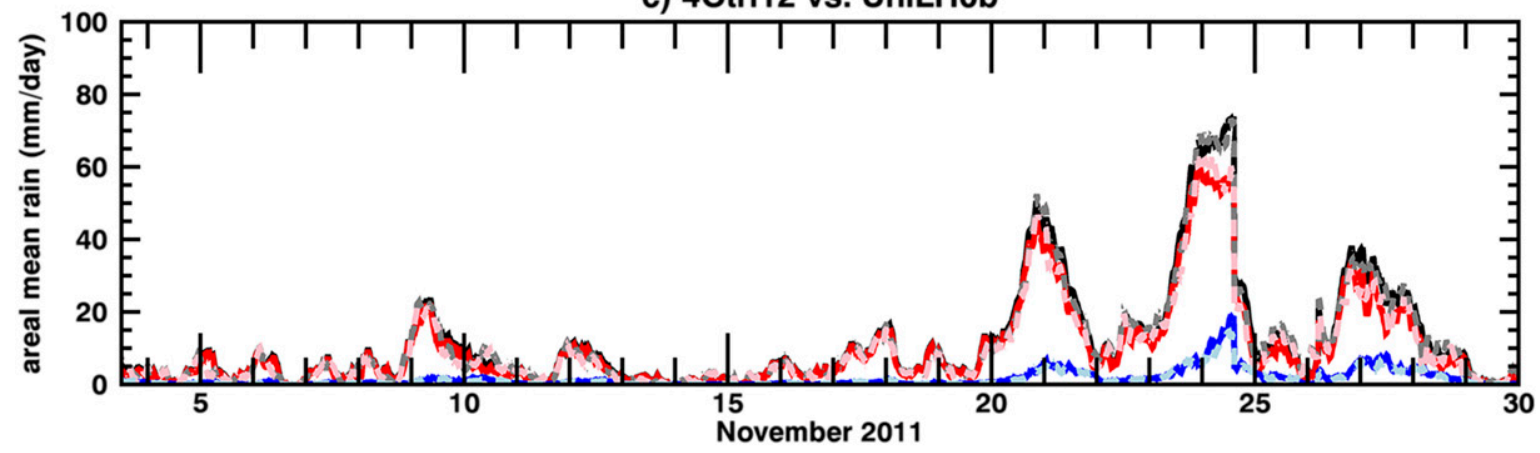

d) 4 Ctrlo vs. 4 Ctrl12

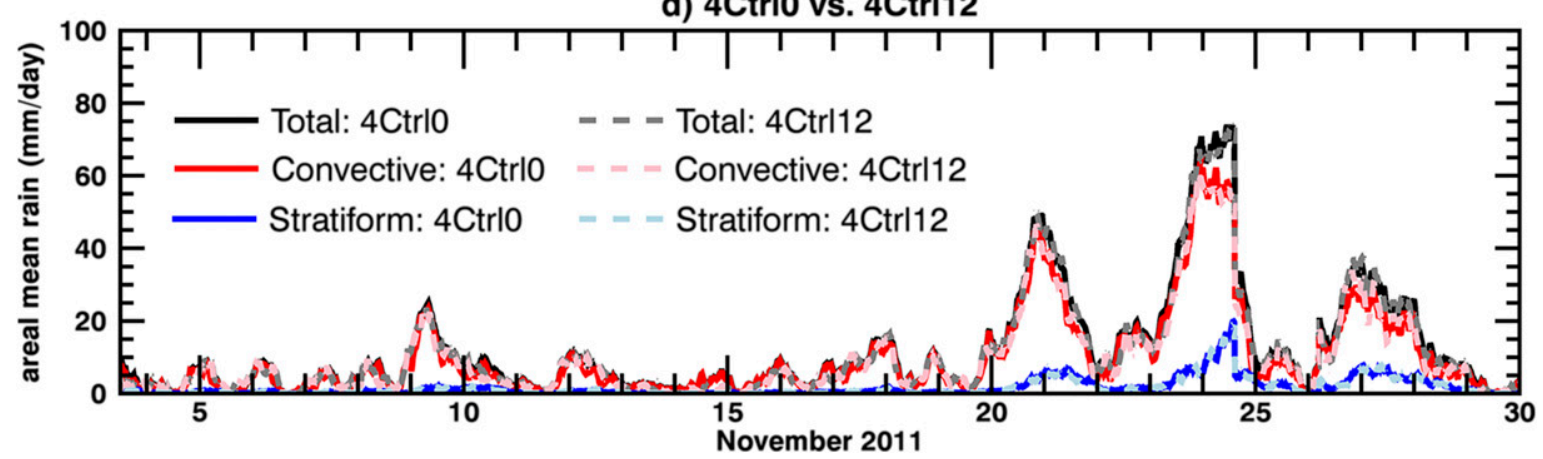

FIG. 17. Area-averaged mean total precipitation (black), convective precipitation (red), and stratiform precipitation (blue) between the (a) 4Ctr10 simulation (solid) and UniLH0a sensitivity simulation (dashed), (b) 4Ctr10 simulation (solid) and UniLH12 sensitivity simulation (dashed), (c) 4Ctrl12 simulation (solid) and UniLH0b sensitivity simulation (dashed), and (d) 4Ctrl0 simulation (solid) and 4Ctrl12 simulation (dashed). The color legend in (a) also applies to (b) and (c). 
1) The relationship between LHFLX and precipitation is insensitive to $\mathrm{MJO}$ regime and cluster size.

2) The LHFLX structure associated with convective clusters is primarily wind driven, in keeping with previous work. However, $q$ contributes to the broader LHFLX structure.

3) The spatial influence of gust-front winds on LHFLXs varies depending on cluster size and MJO regime.

4) Convective organization on the mesoscale and smaller spatial scales is insensitive to convectivescale wind-induced LHFLX feedbacks.

After identifying deep convective clusters in the 1.5Ctrl0 simulation, the relationship between LHFLX and precipitation was described for various cluster sizes and MJO regimes. Despite subtle differences across cluster size and MJO regime, the general LHFLXprecipitation relationship within four hours of cluster identification evolved as follows. Prior to maximum precipitation, maximum LHFLX occurs upwind of precipitation. As the time of maximum precipitation is approached near time zero, maximum precipitation and fluxes become more coincident. Maximum LHFLX values move downstream of maximum precipitation after time zero and leave a "notch" or local minimum of LHFLX underneath and upwind of the maximum precipitation. We interpret this LHFLX-precipitation structure to reflect the constructive versus destructive interference of the convective cold pool gust-front winds with the background wind, and this is supported by our examination of the evolution of wind speed and vectors surrounding the clusters. The influence of gust-front winds on LHFLXs from clusters in the smallest-size quartile during the onset and WWB regime is limited in spatial scale because of the comparatively strong background winds during these regimes compared to the suppressed regime. Larger clusters are able to generate a noticeable gust-front LHFLX signature above the background wind in the onset and WWB regime. Specific humidity, though not as influential to LHFLX on the convective cluster scale, helps set the location and magnitude of minimum LHFLXs prior to maximum surface precipitation.

Convective organization was then compared between 4-km control simulations with interactive fluxes and three 4-km sensitivity simulations that used spatially homogenized LHFLXs to remove small-scale variability in fluxes. Convective organization was quantified using the SCAI developed by Tobin et al. (2012) and the evaluation of convective versus stratiform precipitation area. By both metrics, no discernable change in convective organization between the $4-\mathrm{km}$ control and sensitivity simulations was detected. This suggests-at least for our set of simulations-that convective-scale wind-induced LHFLX feedbacks are not important for organizing convection on the mesoscale and smaller spatial scales. Possible explanations for our results were discussed. The large-scale dynamics or the local mechanical forcing associated with gust fronts may be more relevant than thermodynamic feedbacks for convective organization. The lack of change in the relationship between the gust front and precipitation among the 4-km control and sensitivity simulations and the similar evolution of the two variables for all simulations is consistent with the idea that the dynamics (i.e., mechanical lifting) along the gust front may be more important than thermodynamic feedbacks within the gust front at initiating and organizing new convection. Alternatively, radiative feedbacks, which were not considered in this study, may dominate over surface flux feedbacks, such that homogenization of LHFLX does not produce a firstorder change to convective organization.

Future work will further evaluate the relationship of LHFLX to convective clusters by using forthcoming NASA Cyclone Global Navigation Satellite System (CYGNSS) observations of wind speed. Additional experiments constraining radiative feedbacks will also be conducted. We will also use refined model approaches such as those using the WTG approximation to parameterize large-scale dynamics, removing possible constraints on organization applied through lateral boundary conditions.

Acknowledgments. We would like to acknowledge high-performance computing support from Yellowstone (ark:/85065/d7wd3xhc) provided by NCAR's Computational and Information Systems Laboratory, sponsored by the National Science Foundation. We thank three anonymous reviewers for their constructive comments that improved this work. This work was supported by the NASA CYGNSS program under Grant NNX13AQ50G, the Climate and Large-Scale Dynamics Program of the National Science Foundation under Grant AGS-1025584, and the NOAA ESS Program under Grant NA13OAR4310163. The statements, findings, conclusions, and recommendations do not necessarily reflect the views of NASA, NOAA, or NSF.

\section{REFERENCES}

Araligidad, N. M., and E. D. Maloney, 2008: Wind-driven latent heat flux and the intraseasonal oscillation. Geophys. Res. Lett., 35, L04815, https://doi.org/10.1029/2007GL032746.

Bretherton, C. S., P. N. Blossey, and M. Khairoutdinov, 2005: An energy-balance analysis of deep convective self-aggregation above uniform SST. J. Atmos. Sci., 62, 4273-4292, https://doi.org/ 10.1175/JAS3614.1.

Chen, S. S., and Coauthors, 2016: Aircraft observations of dry air, the ITCZ, convective cloud systems, and cold pools in MJO 
during DYNAMO. Bull. Amer. Meteor. Soc., 97, 405-423, https://doi.org/10.1175/BAMS-D-13-00196.1.

Chuda, T., H. Niino, K. Yoneyama, M. Katsumata, T. Ushiyama, and O. Tsukamoto, 2008: A statistical analysis of surface turbulent heat flux enhancements due to precipitating clouds observed in the tropical western Pacific. J. Meteor. Soc. Japan, 86, 439-457, https://doi.org/10.2151/jmsj.86.439.

Ciesielski, P. E., and Coauthors, 2014: Quality-controlled upper-air sounding dataset for DYNAMO/CINDY/AMIE: Development and corrections. J. Atmos. Oceanic Technol., 31, 741-764, https://doi.org/10.1175/JTECH-D-13-00165.1.

Cotton, W. R., and Coauthors, 2003: RAMS 2001: Current status and future directions. Meteor. Atmos. Phys., 82, 5-29, https:// doi.org/10.1007/s00703-001-0584-9.

Davies, H. C., 1976: A lateral boundary formulation for multi-level prediction models. Quart. J. Roy. Meteor. Soc., 102, 405-418, https://doi.org/10.1002/qj.49710243210.

Dee, D. P., and Coauthors, 2011: The ERA-Interim reanalysis: Configuration and performance of the data assimilation system. Quart. J. Roy. Meteor. Soc., 137, 553-597, https://doi.org/10.1002/qj.828.

DeMott, C. A., N. P. Klingaman, and S. J. Woolnough, 2015: Atmosphere-ocean coupled processes in the Madden-Julian oscillation. Rev. Geophys., 53, 1099-1154, https://doi.org/ 10.1002/2014RG000478.

— J. J. Benedict, N. P. Klingaman, S. J. Woolnough, and D. A. Randall, 2016: Diagnosing ocean feedbacks to the MJO: SSTmodulated surface fluxes and the moist static energy budget. J. Geophys. Res. Atmos., 121, 8350-8373, https://doi.org/ 10.1002/2016JD025098.

de Szoeke, S. P., J. B. Edson, J. R. Marion, C. W. Fairall, and L. Bariteau, 2015: The MJO and air-sea interaction in TOGA COARE and DYNAMO. J. Climate, 28, 597-622, https://doi.org/ 10.1175/JCLI-D-14-00477.1.

Emanuel, K. A., 1987: An air-sea interaction model of intraseasonal oscillations in the tropics. J. Atmos. Sci., 44, 2324-2340, https:// doi.org/10.1175/1520-0469(1987)044<2324:AASIMO>2.0.CO;2.

Esaias, W. E., and Coauthors, 1998: An overview of MODIS capabilities for ocean science observations. IEEE Trans. Geosci. Remote Sens., 36, 1250-1265, https://doi.org/10.1109/36.701076.

Esbensen, S. K., and M. J. McPhaden, 1996: Enhancement of tropical ocean evaporation and sensible heat flux by atmospheric mesoscale systems. J. Climate, 9, 2307-2325, https:// doi.org/10.1175/1520-0442(1996)009<2307:EOTOEA > 2.0.CO;2.

Gentine, P., A. Garelli, S. Park, J. Nie, G. Torri, and Z. Kuang, 2016: Role of surface heat fluxes underneath cold pools. Geophys. Res. Lett., 43, 874-883, https://doi.org/10.1002/2015GL067262.

Gottschalck, J., P. E. Roundy, C. J. Schreck III, A. Vintzileos, and C. Zhang, 2013: Large-scale atmospheric and oceanic conditions during the 2011-12 DYNAMO field campaign. Mon. Wea. Rev., 141, 4173-4196, https://doi.org/10.1175/MWR-D-13-00022.1.

Hagos, S., Z. Feng, S. McFarlane, and L. R. Leung, 2013: Environment and the lifetime of tropical deep convection in a cloud-permitting regional model simulation. J. Atmos. Sci., 70, 2409-2425, https://doi.org/10.1175/JAS-D-12-0260.1.

Harrington, J. Y., 1997: The effects of radiative and microphysical processes on simulated warm and transition season Arctic stratus. Ph.D. dissertation, Dept. of Atmospheric Science, Colorado State University, 289 pp.

Hendon, H. H., and J. Glick, 1997: Intraseasonal air-sea interaction in the tropical Indian and Pacific Oceans. J. Climate, 10, 647-661, https://doi.org/10.1175/1520-0442(1997)010<0647: IASIIT $>2.0 . \mathrm{CO} ; 2$.
Herman, M. J., and D. J. Raymond, 2014: WTG cloud modeling with spectral decomposition of heating. J. Adv. Model. Earth Syst., 6, 1121-1140, https://doi.org/10.1002/2014MS000359.

Holloway, C. E., 2017: Convective aggregation in realistic convective-scale simulations. J. Adv. Model. Earth Syst., 9, 1450-1472, https://doi.org/10.1002/2017MS000980.

— aggregation to diabatic processes in idealized radiative-convective equilibrium simulations. J. Adv. Model. Earth Syst., 8, 166-195, https://doi.org/10.1002/2015MS000511.

Houze, R. A., 2004: Mesoscale convective systems. Rev. Geophys., 42, RG4003, https://doi.org/10.1029/2004RG000150.

Huffman, G. J., and D. T. Bolvin, 2014: TRMM and other data precipitation data set documentation. NASA GSFC Rep., 44 pp., https://pmm.nasa.gov/sites/default/files/document_files/3B42_3B43_ doc_V7.pdf.

, and Coauthors, 2007: The TRMM Multisatellite Precipitation Analysis (TMPA): Quasi-global, multiyear, combined-sensor precipitation estimates at fine scales. J. Hydrometeor., 8, 38-55, https://doi.org/10.1175/JHM560.1.

Jabouille, P., J. L. Redelsperger, and J. P. Lafore, 1996: Modification of surface fluxes by atmospheric convection in the TOGA COARE region. Mon. Wea. Rev., 124, 816-837, https://doi.org/ 10.1175/1520-0493(1996)124<0816:MOSFBA > 2.0.CO;2.

Jeevanjee, N., and D. M. Romps, 2015: Effective buoyancy, inertial pressure, and the mechanical generation of boundary layer mass flux by cold pools. J. Atmos. Sci., 72, 3199-3213, https:// doi.org/10.1175/JAS-D-14-0349.1.

Jiang, X., and Coauthors, 2015: Vertical structure and physical processes of the Madden-Julian oscillation: Exploring key model physics in climate simulations. J. Geophys. Res. Atmos., 120, 4718-4748, https://doi.org/10.1002/2014JD022375.

Johnson, R. H., and P. E. Ciesielski, 2013: Structure and properties of Madden-Julian oscillations deduced from DYNAMO sounding arrays. J. Atmos. Sci., 70, 3157-3179, https://doi.org/ 10.1175/JAS-D-13-065.1.

Jones, C., and B. C. Weare, 1996: The role of low-level moisture convergence and ocean latent heat fluxes in the Madden and Julian oscillation: An observational analysis using ISCCP data and ECMWF analyses. J. Climate, 9, 3086-3104, https://doi.org/ 10.1175/1520-0442(1996)009<3086:TROLLM > 2.0.CO;2.

Kim, D., J. Kug, and A. H. Sobel, 2014: Propagating versus nonpropagating Madden-Julian oscillation events. J. Climate, 27, 111-125, https://doi.org/10.1175/JCLI-D-13-00084.1.

Kiranmayi, L., and E. D. Maloney, 2011: Intraseasonal moist static energy budget in reanalysis data. J. Geophys. Res., 116, D21117, https://doi.org/10.1029/2011JD016031.

Klingaman, N. P., X. Jiang, P. K. Xavier, J. Petch, D. Waliser, and S. J. Woolnough, 2015: Vertical structure and physical processes of the Madden-Julian oscillation: Synthesis and summary. J. Geophys. Res. Atmos., 120, 4671-4689, https://doi.org/ 10.1002/2015JD023196.

Li, Z., P. Zuidema, and P. Zhu, 2014: Simulated convective invigoration processes at trade wind cumulus cold pool boundaries. J. Atmos. Sci., 71, 2823-2841, https://doi.org/10.1175/ JAS-D-13-0184.1.

Madden, R. A., and P. R. Julian, 1994: Observations of the 4050-day tropical oscillation-A review. Mon. Wea. Rev., 122, 814-837, https://doi.org/10.1175/1520-0493(1994)122<0814: OOTDTO $>2.0 . \mathrm{CO} ; 2$.

Maloney, E. D., and S. K. Esbensen, 2003: The amplification of east Pacific Madden-Julian oscillation convection and wind anomalies 
during June-November. J. Climate, 16, 3482-3497, https://doi.org/ 10.1175/1520-0442(2003)016<3482:TAOEPM >2.0.CO;2.

— , and A. H. Sobel, 2004: Surface fluxes and ocean coupling in the tropical intraseasonal oscillation. J. Climate, 17, 4368-4386, https://doi.org/10.1175/JCLI-3212.1.

_ east Pacific wind-induced ocean-atmosphere exchange in the intraseasonal oscillation. J. Climate, 18, 568-584, https://doi.org/ 10.1175/JCLI-3280.1.

$\longrightarrow$, and — 2007: Satellite and buoy observations of boreal summer intraseasonal variability in the tropical northeast Pacific. Mon. Wea. Rev., 135, 3-19, https://doi.org/10.1175/MWR3271.1.

- A. H. Sobel, and W. M. Hannah, 2010: Intraseasonal variability in an aquaplanet general circulation model. J. Adv. Model. Earth Syst., 2 (2), https://doi.org/10.3894/JAMES.2010.2.5.

Mapes, B. E., and R. A. Houze Jr., 1993: Cloud clusters and superclusters over the oceanic warm pool. Mon. Wea. Rev., 121, 1398-1416, https://doi.org/10.1175/1520-0493(1993)121<1398: CCASOT $>2.0 . \mathrm{CO} ; 2$.

Meyers, M. P., R. L. Walko, J. Y. Harrington, and W. R. Cotton, 1997: New RAMS cloud microphysics parameterization. Part II: The two-moment scheme. Atmos. Res., 45, 3-39, https://doi.org/ 10.1016/S0169-8095(97)00018-5.

Muller, C. J., and I. M. Held, 2012: Detailed investigation of the selfaggregation of convection in cloud-resolving simulations. J. Atmos. Sci., 69, 2551-2565, https://doi.org/10.1175/JAS-D-11-0257.1.

Neelin, J. D., I. M. Held, and K. H. Cook, 1987: Evaporation-wind feedback and low-frequency variability in the tropical atmosphere. J. Atmos. Sci., 44, 2341-2348, https://doi.org/10.1175/ 1520-0469(1987)044<2341:EWFALF $>2.0 . C O ; 2$.

Raymond, D. J., 2001: A new model of the Madden-Julian oscillation. J. Atmos. Sci., 58, 2807-2819, https://doi.org/10.1175/ 1520-0469(2001)058<2807:ANMOTM>2.0.CO;2.

Redelsperger, J., F. Guichard, and S. Mondon, 2000: A parameterization of mesoscale enhancement of surface fluxes for large-scale models. J. Climate, 13, 402-421, https://doi.org/ 10.1175/1520-0442(2000)013<0402:APOMEO>2.0.CO;2.

Riley, E. M., B. E. Mapes, and S. N. Tulich, 2011: Clouds associated with the Madden-Julian oscillation: A new perspective from CloudSat. J. Atmos. Sci., 68, 3032-3051, https://doi.org/ 10.1175/JAS-D-11-030.1.

Riley Dellaripa, E. M., and E. D. Maloney, 2015: Analysis of MJO wind-flux feedbacks in the Indian Ocean using RAMA buoy observations. J. Meteor. Soc. Japan, 93A, 1-20, https://doi.org/ 10.2151/jmsj.2015-021.

Ruppert, J. H., and R. H. Johnson, 2015: Diurnally modulated cumulus moistening in the preonset stage of the MaddenJulian oscillation during DYNAMO. J. Atmos. Sci., 72, 1622-1647, https://doi.org/10.1175/JAS-D-14-0218.1.

_ , and _ 2016: On the cumulus diurnal cycle over the tropical warm pool. J. Adv. Model. Earth Syst., 8, 669-690, https:// doi.org/10.1002/2015MS000610.

Saleeby, S. M., and W. R. Cotton, 2004: A large-droplet mode and prognostic number concentration of cloud droplets in the Colorado State University Regional Atmospheric Modeling System (RAMS). Part I: Module descriptions and supercell test simulations. J. Appl. Meteor., 43, 182-195, https://doi.org/ 10.1175/1520-0450(2004)043<0182:ALMAPN $>2.0 . C O ; 2$. , and S. C. van den Heever, 2013: Developments in the CSU-RAMS aerosol model: Emissions, nucleation, regeneration, deposition, and radiation. J. Appl. Meteor. Climatol., 52 2601-2622, https://doi.org/10.1175/JAMC-D-12-0312.1.
Saxen, T. R., and S. A. Rutledge, 1998: Surface fluxes and boundary layer recovery in TOGA COARE: Sensitivity to convective organization. J. Atmos. Sci., 55, 2763-2781, https://doi.org/ 10.1175/1520-0469(1998)055<2763:SFABLR $>2.0$. CO;2.

Schumacher, C., and R. A. Houze, 2003: Stratiform rain in the tropics as seen by the TRMM Precipitation Radar. J. Climate, 16, 1739-1756, https://doi.org/10.1175/1520-0442(2003)016<1739: SRITTA $>2.0 . \mathrm{CO} ; 2$.

Skyllingstad, E. D., and S. P. de Szoeke, 2015: Cloud-resolving large-eddy simulation of tropical convective development and surface fluxes. Mon. Wea. Rev., 143, 2441-2458, https://doi.org/ 10.1175/MWR-D-14-00247.1.

Sobel, A., and E. Maloney, 2012: An idealized semi-empirical framework for modeling the Madden-Julian oscillation. J. Atmos. Sci., 69, 1691-1705, https://doi.org/10.1175/ JAS-D-11-0118.1.

, and - 2013: Moisture modes and the eastward propagation of the MJO. J. Atmos. Sci., 70, 187-192, https://doi.org/ 10.1175/JAS-D-12-0189.1.

_ - J. Nilsson, and L. M. Polvani, 2001: The weak temperature gradient approximation and balanced tropical moisture waves. J. Atmos. Sci., 58, 3650-3665, https://doi.org/10.1175/ 1520-0469(2001)058<3650:TWTGAA > 2.0.CO;2.

, E. D. Maloney, G. Bellon, and D. M. Frierson, 2008: The role of surface heat fluxes in tropical intraseasonal oscillations. Nat. Geosci., 1, 653-657, https://doi.org/10.1038/ngeo312.

$\ldots, \ldots, \ldots$, and 2010: Surface fluxes and tropical intraseasonal variability: A reassessment. J. Adv. Model. Earth Syst., 2 (1), https://doi.org/10.3894/JAMES.2010.2.2.

- S. Wang, and D. Kim, 2014: Moist static energy budget of the MJO during DYNAMO. J. Atmos. Sci., 71, 4276-4291, https:// doi.org/10.1175/JAS-D-14-0052.1.

Steiner, M., R. A. Houze, and S. E. Yuter, 1995: Climatological characterization of three-dimensional storm structure from operational radar and rain gauge data. J. Appl. Meteor., 34, 1978-2007, https://doi.org/10.1175/1520-0450(1995)034<1978: CCOTDS $>2.0 . \mathrm{CO} ; 2$.

Tobin, I., S. Bony, and R. Roca, 2012: Observational evidence for relationships between the degree of aggregation of deep convection, water vapor, surface fluxes, and radiation. J. Climate, 25, 6885-6904, https://doi.org/10.1175/JCLI-D-11-00258.1.

Tompkins, A. M., 2001: Organization of tropical convection in low vertical wind shears: The role of cold pools. J. Atmos. Sci., 58, 1650-1672, https://doi.org/10.1175/1520-0469(2001)058<1650: OOTCIL $>2.0 . \mathrm{CO} ; 2$.

, and G. C. Craig, 1998: Radiative-convective equilibrium in a three-dimensional cloud-ensemble model. Quart. J. Roy. Meteor. Soc., 124, 2073-2097, https://doi.org/10.1002/qj.49712455013.

Torri, G., Z. Kuang, and Y. Tian, 2015: Mechanisms for convection triggering by cold pools. Geophys. Res. Lett., 42, 1943-1950, https://doi.org/10.1002/2015GL063227.

Walko, R. L., W. R. Cotton, M. P. Meyers, and J. Y. Harrington, 1995: New RAMS cloud microphysics parameterization part I: The single-moment scheme. Atmos. Res., 38, 29-62, https:// doi.org/10.1016/0169-8095(94)00087-T.

, and Coauthors, 2000: Coupled atmosphere-biophysicshydrology models for environmental modeling. J. Appl. Meteor., 39, 931-944, https://doi.org/10.1175/1520-0450(2000)039<0931: CABHMF $>2.0 . \mathrm{CO} ; 2$.

Wang, S., A. H. Sobel, and J. Nie, 2016: Modeling the MJO in a cloud-resolving model with parameterized large-scale dynamics: Vertical structure, radiation, and horizontal advection 
of dry air. J. Adv. Model. Earth Syst., 8, 121-139, https://doi.org/ 10.1002/2015MS000529.

Wing, A. A., and K. A. Emanuel, 2014: Physical mechanisms controlling self-aggregation of convection in idealized numerical modeling simulations. J. Adv. Model. Earth Syst., 6, 59-74, https://doi.org/10.1002/2013MS000269.

- and T. W. Cronin, 2016: Self-aggregation of convection in long channel geometry. Quart. J. Roy. Meteor. Soc., 142, 1-15, https://doi.org/10.1002/qj.2628.

$\mathrm{Wu}, \mathrm{X}$., and S. Guimond, 2006: Two- and three-dimensional cloudresolving model simulations of the mesoscale enhancement of surface heat fluxes by precipitating deep convection. J. Climate, 19, 139-149, https://doi.org/10.1175/JCL3610.1.

Xu, W., and S. A. Rutledge, 2014: Convective characteristics of the Madden-Julian oscillation over the central Indian Ocean observed by shipborne radar during DYNAMO. J. Atmos. Sci., 71, 2859-2877, https://doi.org/10.1175/ JAS-D-13-0372.1.

Yokoi, S., M. Katsumata, and K. Yoneyama, 2014: Variability in surface meteorology and air-sea fluxes due to cumulus convective systems observed during CINDY/DYNAMO. J. Geophys. Res. Atmos., 119, 2064-2078, https://doi.org/ 10.1002/2013JD020621.

Yoneyama, K., C. Zhang, and C. N. Long, 2013: Tracking pulses of the Madden-Julian oscillation. Bull. Amer. Meteor. Soc., 94, 1871-1891, https://doi.org/10.1175/BAMS-D-12-00157.1.

Young, G. S., S. M. Perugini, and C. W. Fairall, 1995: Convective wakes in the equatorial western Pacific during TOGA. Mon. Wea. Rev., 123, 110-123, https://doi.org/10.1175/ 1520-0493(1995)123<0110:CWITEW>2.0.CO;2.

Yuan, J., and R. A. Houze, 2010: Global variability of mesoscale convective system anvil structure from A-train satellite data. J. Climate, 23, 5864-5888, https://doi.org/10.1175/ 2010JCLI3671.1.

Yuter, S. E., and R. A. Houze, 1997: Measurements of raindrop size distributions over the Pacific warm pool and implications for $Z-R$ relations. J. Appl. Meteor., 36, 847-867, https://doi.org/ 10.1175/1520-0450(1997)036<0847:MORSDO > 2.0.CO;2.

Zhang, C. D., 2005: Madden-Julian oscillation. Rev. Geophys., 43, RG2003, https://doi.org/10.1029/2004RG000158. 